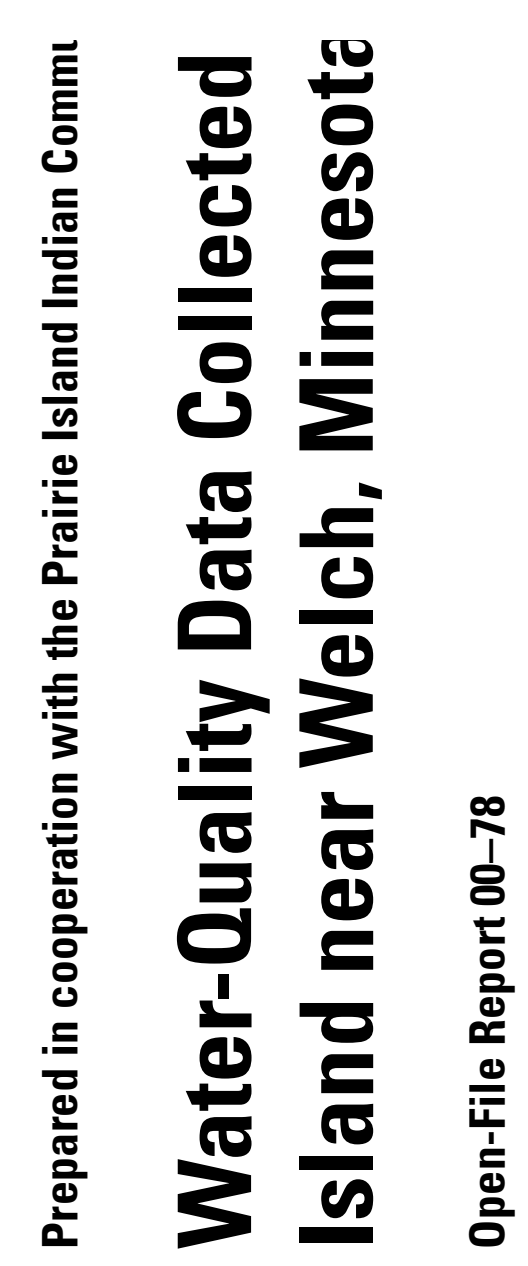

Water-Quality Data Collected on Prairie Island near Welch, Minnesota, 1998-99 
U.S. Department of the Interior

U.S. Geological Survey

\section{Water-Quality Data Collected on Prairie Island near Welch, Minnesota, 1998-99}

By Thomas A. Winterstein

Open-File Report 00-78

Prepared in cooperation with the Prairie Island Indian Community 


\section{U.S. Department of the Interior}

Bruce Babbitt, Secretary

\section{U.S. Geological Survey}

Charles G. Groat, Director

Use of trade, product, industry, or firm names in this report is for descriptive or location purposes only and does not constitute endorsement of products by the U.S. Government.

Mounds View, Minnesota, 2000

For additional information write to:

District Chief

U.S. Geological Survey, WRD

2280 Woodale Drive

Mounds View MN 55112

Copies of this report can be purchased from:

U.S. Geological Survey

Branch of Information Services

Box 25286

Federal Center

Denver CO 80225

For more information on the USGS in Minnesota, you may connect to the Minnesota District home page at http://mn.water.usgs.gov

For more information on all USGS reports and products (including maps,

images, and computerized data), call 1-888-ASK-USGS

Open-File Report 00-78 


\section{CONTENTS}

Abstract.

Introduction

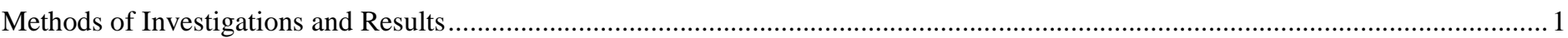

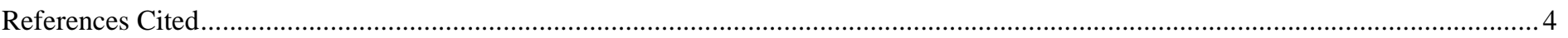

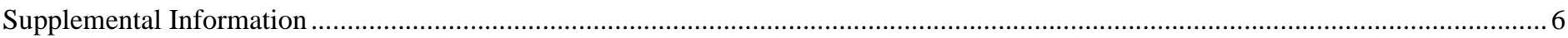

\section{ILLUSTRATIONS}

Figure 1. Map showing location of study area, surface-water sites, and monitoring wells, Prairie Island Indian Community, Minnesota

Figure 2. Piper diagram showing percentage distribution of major ion concentrations determined for water sampled from 17 wells,

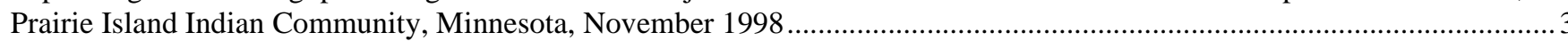

Figure 3. Graph showing stage and precipitation at Sturgeon and Clear Lakes, Prairie Island, Minnesota, August 1998-June 1999 ......5

\section{TABLES}

1. Location of monitoring wells, Prairie Island Indian Community, Minnesota, 1998-99 7

2. Construction information for monitoring wells, Prairie Island Indian Community, Minnesota, 1998 ......................................... 8

3. Well logs of monitoring wells, Prairie Island Indian Community, Minnesota, 1998 ................................................................... 9

4. Water-quality data collected from monitoring wells, Prairie Island Indian Community, Minnesota, 1998 .................................... 16

5. Pesticide data, Prairie Island Indian Community, Minnesota, 1998 ......................................................................................... 19

6. Relative percent difference between concentrations of constituents in the sample and replicate sample from well 1, Prairie Island Indian Community, Minnesota, 1998.

7. Results of semiquantitative immunoassay screens for atrazine and related triazine compounds, Prairie Island Indian Community, Minnesota, 1998

8. Calculated corrected concentrations for selected triazine herbicides, Prairie Island Indian Community, Minnesota, 1998 ................ 21

9. Location and description of surface-water sites, Prairie Island Indian Community, Minnesota, 1998 .........................................21

10. Measured ground- and surface-water altitudes, Prairie Island Indian Community, Minnesota, 1998-99......................................22 


\section{CONVERSION FACTORS, ABBREVIATIONS, AND UNITS OF CONCENTRATION}

Multiply inch-pound unit

inch (in.)

foot $(\mathrm{ft})$

gallon (gal)

degrees Fahrenheit $\left({ }^{\circ} \mathrm{F}\right)$
By

2.54

0.3048

3.785

$5 / 9 \times\left({ }^{\circ} \mathrm{F}-32\right)$ $\underline{\text { To obtain metric unit }}$

centimenter

meter

liter

degrees Celsius

Sea level: The North American Vertical Datum of 1988 is the vertical control datum established in 1991 by the minimum-constraint adjustment of the Canadian-Mexican-U.S. leveling observations. It held fixed the height of the primary tidal bench mark, referenced to the new International Great Lakes Datum of 1985 local mean sea level height value, at Father Point/Rimouski, Quebec, Canada.

National Geodetic Vertical Datum of 1988 (NGVD of 1988).

Chemical concentrations are given in metric units. Chemical concentrations of substances in water are given in milligrams per liter $(\mathrm{mg} / \mathrm{L})$ or micrograms per liter $(\mu \mathrm{g} / \mathrm{L})$. Milligrams per liter is a unit expressing the concentration of chemical constituents in solution as mass (milligrams) of solute per unit volume (liter) of water. Micrograms per liter is a unit expressing the concentration of chemical constituents in solution as mass (micrograms) of solute per unit volume (liter) of water. One thousand micrograms per liter is equivalent to one milligram per liter. 


\title{
Water-Quality Data Collected on Prairie Island near Welch, Minnesota, 1998-99
}

\author{
By Thomas A. Winterstein
}

\section{ABSTRACT}

This report presents the water-quality data collected during 1998-99 from the land owned by the Prairie Island Indian Community at the northern end of Prairie Island, Minnesota. The data were collected by the U.S. Geological Survey in cooperation with the Prairie Island Indian Community. Seventeen monitoring wells were installed by the U.S. Geological Survey in 1998. Fifteen of the wells were installed with the screen at the water-table. The well screens for the other two wells were approximately 26 and 56 feet below the water table. Samples were collected from the wells in 1998. The water-quality properties and constituents determined for the 17 wells include temperature, $\mathrm{pH}$, specific conductance, dissolved oxygen, alkalinity, major ions. nutrients, and iron and manganese. Water samples collected from two of the wells were analyzed for common agricultural pesticides. In addition, semiquantitative immunoassay screens for presence of atrazine and related triazine herbicides were conducted on samples from all 17 wells. Water-surface altitudes were measured during 1999 in the 17 wells and at 8 surface-water sites

\section{INTRODUCTION}

The Prairie Island Indian Community is located on Prairie Island between the Vermillion and Mississippi Rivers in Goodhue County, Minnesota (fig. 1). The U.S. Geological Survey (USGS) conducted a study from 1998 through 1999, in cooperation with the Prairie Island Indian Community, to determine the quality of water and the elevation of the water table at the northern end of Prairie Island. The USGS installed 17 monitoring wells during August and September 1998 (fig. 1). Water was collected from wells for analysis during November and December 1998. Water-surface altitudes were measured during 1999 in 17 wells and at 8 surface-water sites (fig. 1).

The purpose of this report is to present the data collected by the USGS during 1998-99. The water-quality properties and constituents determined for the 17 wells include temperature, $\mathrm{pH}$, specific conductance, dissolved oxygen, alkalinity, major ions, nutrients, and iron and manganese. Water samples collected from two of the wells were analyzed for common agricultural pesticides. In addition, semiquantitative immunoassay screens for presence of atrazine and related triazine herbicides were conducted on samples from all 17 wells.

\section{METHODS OF INVES- TIGATION AND RESULTS}

Seventeen 2-inch diameter monitoring wells were installed during August and September 1998 (table 1, all tables at the back of the report). The wells were surveyed to determine elevation above mean sea level. Well construction details and well $\operatorname{logs}$ are in tables 2 and 3, respectively. Fifteen of the wells were installed with the well screen at the water table. The well screens for the other wells, wells $12 \mathrm{a}$ and $12 \mathrm{~b}$, were approximately 26 and 55 feet below the water table, respectively.

Water samples for water-quality analysis were collected from the 17 monitoring wells during November and December 1998. The samples were collected, preserved, and stored in accordance with procedures described in Koterba and others (1995). The samples were analyzed for chemical constituents at the U.S. Geological Survey National Water-Quality Laboratory (NWQL) in Arvada, Colorado. The samples were analyzed for major ions (fig. 2), nutrients (table 4), and iron and manganese. Samples collected from two of the wells, wells 1 and 14, were analyzed for common agricultural pesticides (table 5).
Field measurements were made in accordance with procedures described in Wilde and Radtke (1998). Field measurements of temperature, $\mathrm{pH}$, specific conductance, and dissolved oxygen were made with a portable, multiparameter meter calibrated at the start of each sampling day. Alkalinity was determined by incremental titration.

Two quality assurance samples were collected. A replicate sample was collected from well 1 (table 4). Replicate samples are collected to assess the quality, reliability, and precision (reproducibility) of the data generated by the analysis of the samples for chemical constituents. The relative percent difference between the values for the sample and the replicate sample are shown in table 6 . The relative percent difference was calculated as

$\left[\left(\mathrm{X}_{1}-\mathrm{X}_{2}\right) /\left(\left(\mathrm{X}_{1}+\mathrm{X}_{2}\right) / 2\right)\right] * 100$, where $\mathrm{X}_{1}$ is the value for the sample and $X_{2}$ is the value for the replicate sample.

A field blank was collected before well 3 was sampled by passing inorganicfree, deionized water through all sample equipment contacted by the actual sample (table 4). Field blanks are collected to ensure that equipment cleaning between sampling sites remove all contamination from the previous site, that sampling and sample-processing procedures do not contaminate the equipment, and that transporting and handling the sampling 

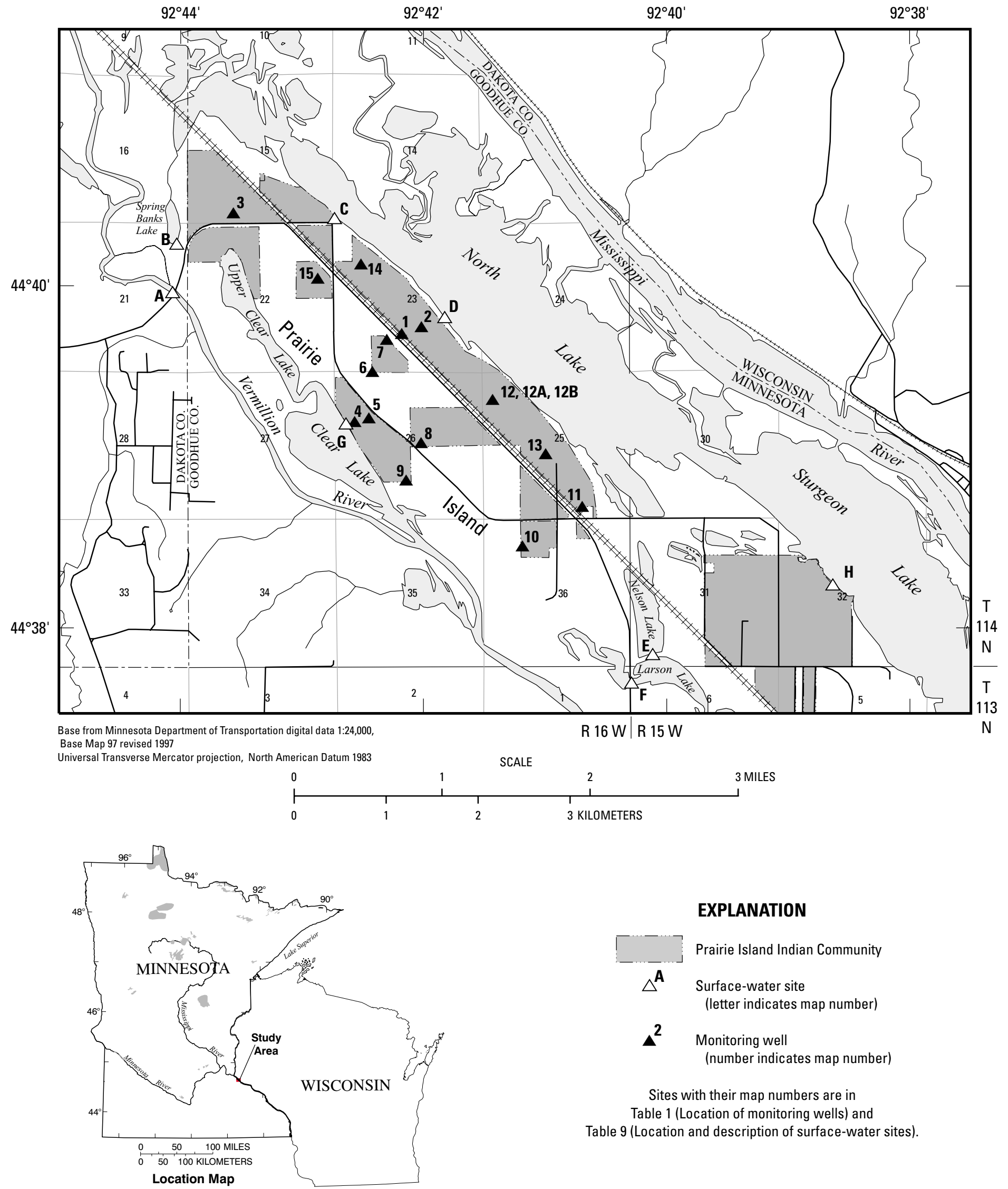

\section{EXPLANATION}

Prairie Island Indian Community

$\triangle$ Surface-water site

(letter indicates map number)

$\mathbf{A}^{2}$ Monitoring well

(number indicates map number)

Sites with their map numbers are in

Table 1 (Location of monitoring wells) and

Table 9 (Location and description of surface-water sites).

Figure 1. Location map, study area, surface-water sites, and monitoring wells, Prairie Island Indian Community, Minnesota. 


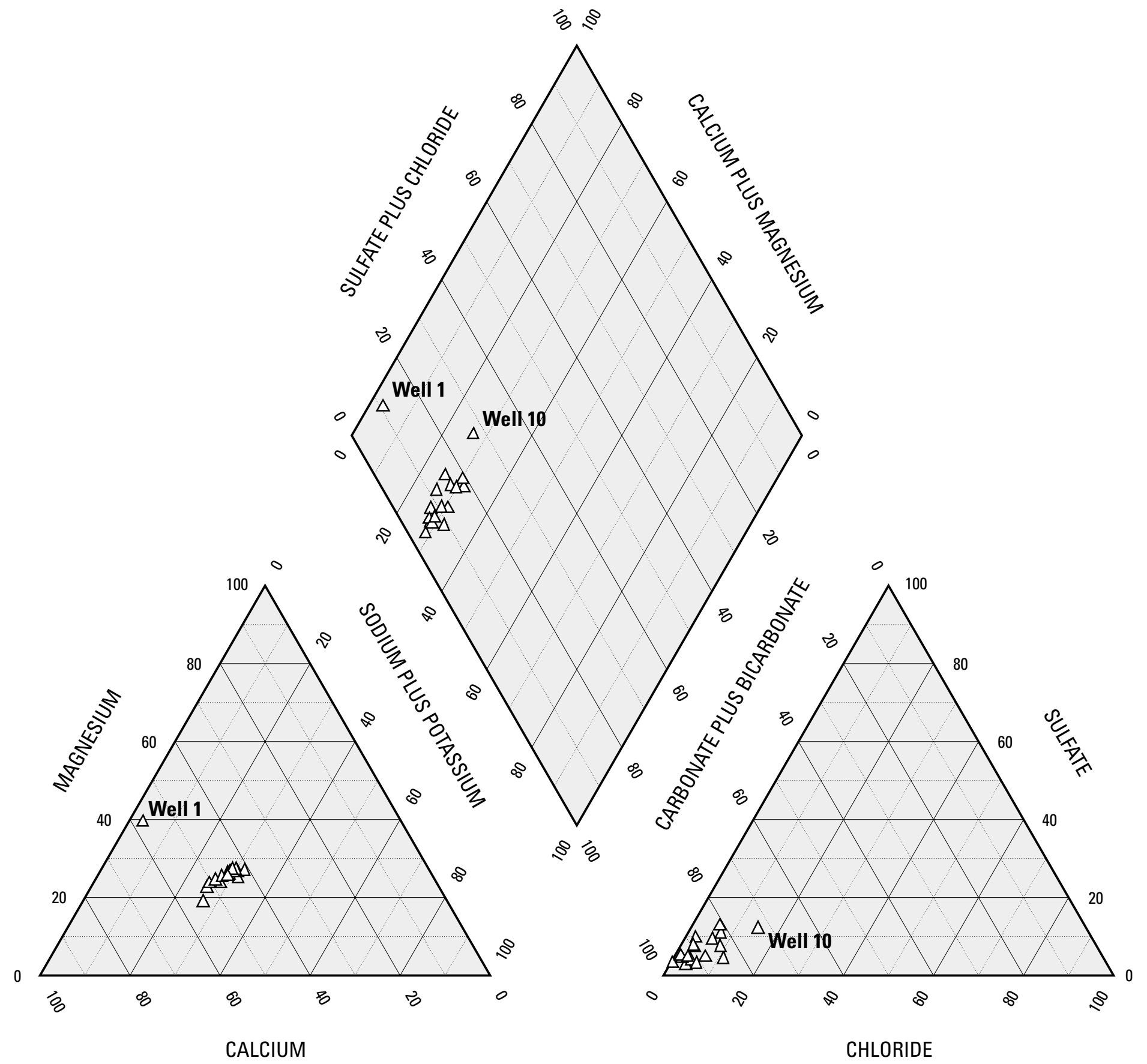

PERCENT OF TOTAL MILLIEQUIVALENTS PER LITER

Figure 2. Percentage distribution of major ion concentrations determined for water sampled from 17 wells, Prairie Island Indian Community, Minnesota, November 1998. 
equipment between sites does not contaminate the equipment. The concentrations of analyzed constituents in the field blank were below the detection limit or very low compared to the concentrations of the constituents in the samples from the wells. This indicates that the samples were not contaminated by the sampling and equipment cleaning procedures used. The only exception was for dissolved nitrogen ammonia. The concentration in the field blank was just above the detection limit and close to the reported concentrations in the samples from the wells.

The specific conductance measured in the field was significantly different from the specific conductance measured by the NWQL for the samples collected from wells $3,4,11$, and 15 . Review of the field notes and the data indicates that the field values are incorrect and that the specific conductance measured by the NWQL should be used for these samples.

Water from the 17 wells were screened for atrazine and related triazine compounds at the Minnesota District Office of the USGS. An enzyme linked immunoassay test, Atrazine RaPID Assay from Strategic Diagnostics Inc., was used to test the samples for the presence of atrazine and related triazine compounds. The results of the tests are in table 7 .

Samples from two of the wells, 1 and 14 , were analyzed by the NWQL for atrazine, deethylatrazine, and simazine (table 5). However, the laboratory experienced problems with the analysis and had low recovery of the spiked surrogates used for quality control, indicating that the measured concentrations of atrazine, deethylatrazine, and simazine were too low (Steven Smith, U.S. Geological Survey Water Quality Laboratory, written commun., 1999). In table 5 the concentrations for these compounds are the low, analytical values; they were flagged as estimated concentrations by the NWQL. Mr. Smith calculated corrected concentrations for these compounds based upon the recovery rates of the surrogates. The calculated corrected concentrations are shown in table 8 .

Eight reference points for determining surface-water elevations were installed and surveyed to mean sea level (table 9, and fig. 1).

Water levels were measured in the 17 wells and at the 8 surface water sites. Precipitation was measured at 2 of the surface-water sites, Clear Lake and Sturgeon Lake (sites $\mathrm{G}$ and $\mathrm{H}$ ). The results are in table 10 and figure 3.

\section{REFERENCES CITED}

Koterba, M.T., Wilde, F.D., and Lapham, W.W., 1995, Ground-water data-collection protocols and procedures for the National Water-Quality Assessment Program-Collection and documentation of water-quality samples and related data: U.S. Geological Survey Open-File Report 95-399, $113 \mathrm{p}$.

Wilde, F.D., and Radtke, D.B., eds., 1998, Field measurements: U.S. Geological Survey, Handbooks for WaterResources Investigations, book 9, chapter A6, unpaged. 

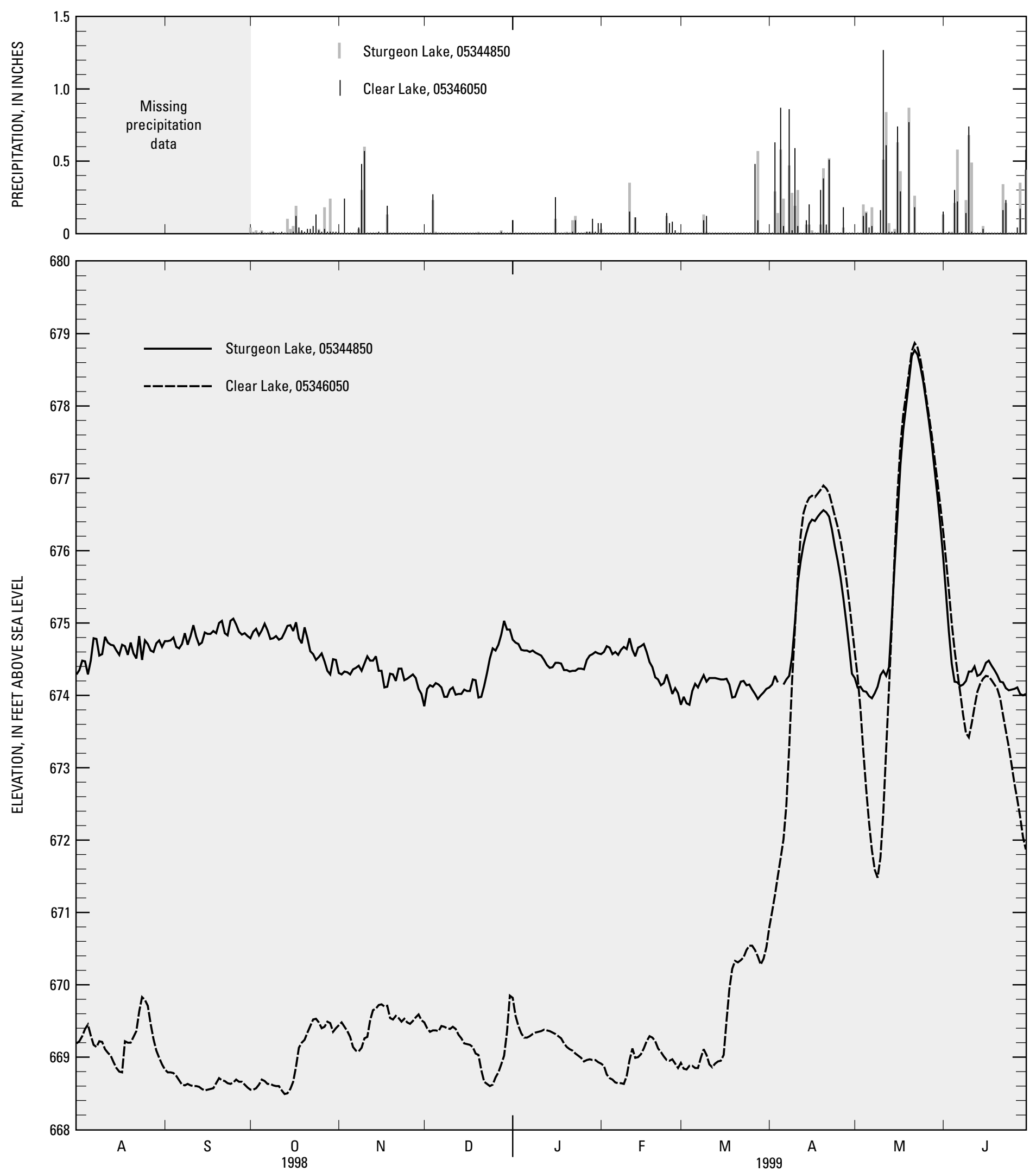

Figure 3. Stage and precipitation at Sturgeon and Clear Lakes, Prairie Island, Minnesota, August 1998-June 1999. 
Supplemental Information 
Table 1. Location of monitoring wells, Prairie Island Indian Community, Minnesota, 1998-99

[MGS, Minnesota Geological Survey]

\begin{tabular}{|c|c|c|c|c|c|}
\hline $\begin{array}{l}\text { Well } \\
\text { (shown in } \\
\text { figure 1) }\end{array}$ & Station number & $\begin{array}{c}\text { MGS } \\
\text { unique } \\
\text { well } \\
\text { number }\end{array}$ & $\begin{array}{c}\text { Longitude } \\
\text { (west longitude) }\end{array}$ & $\begin{array}{c}\text { Latitude } \\
\text { (north latitude) }\end{array}$ & $\begin{array}{l}\text { Township, range, section, quarter section } \\
\text { (quarter sections are listed from largest to } \\
\text { smallest) }\end{array}$ \\
\hline 1 & 443944092421101 & 612783 & $92^{\circ} 42^{\prime} 11^{\prime \prime}$ & $44^{\circ} 39^{\prime} 44^{\prime \prime}$ & 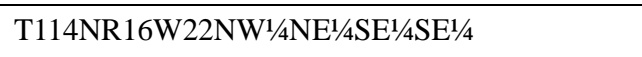 \\
\hline 2 & 443946092420201 & 612782 & $92^{\circ} 42^{\prime} 02^{\prime \prime}$ & $44^{\circ} 39^{\prime} 46^{\prime \prime}$ & T114NR16W23NE $1 / 4 \mathrm{NW}^{1 / 4} \mathrm{SW}^{1 / 4} \mathrm{NE}^{1 / 4}$ \\
\hline 3 & 444026092433501 & 612779 & $92^{\circ} 43^{\prime} 35^{\prime \prime}$ & $44^{\circ} 40^{\prime} 26^{\prime \prime}$ & T114NR16W15SW1/4SE1/4SW1/4NW1/4 \\
\hline 4 & 443912092423501 & 612787 & $92^{\circ} 42^{\prime} 35^{\prime \prime}$ & $44^{\circ} 39^{\prime} 12^{\prime \prime}$ & T114NR16W26NW1/4SW1/4NE $1 / 4 \mathrm{SE}^{1 / 4}$ \\
\hline 5 & 443914092422801 & 612786 & $92^{\circ} 42^{\prime} 28^{\prime \prime}$ & $44^{\circ} 39^{\prime} 14^{\prime \prime}$ & T114NR16W26NW1/4SW1/4NE $1 / 4 \mathrm{NE}^{1 / 4}$ \\
\hline 6 & 443930092422601 & 612785 & $92^{\circ} 42^{\prime} 26^{\prime \prime}$ & $44^{\circ} 39^{\prime} 30^{\prime \prime}$ & T114NR16W23SW1/4SE1/4SW1/4SW1/4 \\
\hline 7 & 443941092421801 & 612784 & $92^{\circ} 42^{\prime} 18^{\prime \prime}$ & $44^{\circ} 39^{\prime} 41^{\prime \prime}$ & $\mathrm{T} 114 \mathrm{NR}^{2} 6 \mathrm{~W} 23 \mathrm{SW}^{1} / 4 \mathrm{SE}^{1} / 4 \mathrm{NW}^{1 / 4} \mathrm{NE}^{1 / 4}$ \\
\hline 8 & 443905092420201 & 612788 & $92^{\circ} 42^{\prime} 02^{\prime \prime}$ & $44^{\circ} 39^{\prime} 05^{\prime \prime}$ & $\mathrm{T}^{114 N R} 16 \mathrm{~W} 26 \mathrm{NE}^{1 / 4} \mathrm{SW}^{1 / 4} \mathrm{SW}^{1 / 4} \mathrm{SE}^{1 / 4}$ \\
\hline 9 & 443852092420901 & 612789 & $92^{\circ} 42^{\prime} 09^{\prime \prime}$ & $44^{\circ} 38^{\prime} 52^{\prime \prime}$ & 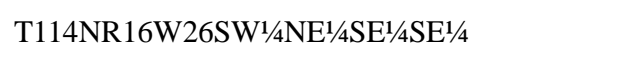 \\
\hline 10 & 443829092411201 & 612793 & $92^{\circ} 41^{\prime} 12^{\prime \prime}$ & $44^{\circ} 38^{\prime} 29^{\prime \prime}$ & T114NR16W36NW1/4NE1/4SW1/4NW1/4 \\
\hline 11 & 443843092404301 & 612792 & $92^{\circ} 40^{\prime} 43^{\prime \prime}$ & $44^{\circ} 38^{\prime} 43^{\prime \prime}$ & T114NR16W25SE1/4SW1/4SE1/4NW1/4 \\
\hline 12 & 443920092412701 & 612790 & $92^{\circ} 41^{\prime} 27^{\prime \prime}$ & $44^{\circ} 39^{\prime} 20^{\prime \prime}$ & T114NR16W25NW'1/4NW1/4SW1/4NW1/4 \\
\hline $12 \mathrm{a}$ & 443920092412702 & 612796 & $92^{\circ} 41^{\prime} 27^{\prime \prime}$ & $44^{\circ} 39^{\prime} 20^{\prime \prime}$ & T114NR16W25NW'1/4NW1/4SW1/4NW1/4 \\
\hline $12 \mathrm{~b}$ & 443920092412703 & 612797 & $92^{\circ} 41^{\prime} 27^{\prime \prime}$ & $44^{\circ} 39^{\prime} 20^{\prime \prime}$ & T114NR16W25NW'1/4NW1/4SW1/4NW1/4 \\
\hline 13 & 443901092410001 & 612791 & $92^{\circ} 41^{\prime} 00^{\prime \prime}$ & $44^{\circ} 39^{\prime} 01^{\prime \prime}$ & T114NR16W25SW1/4NE1/4NE $1 / 4 \mathrm{NW}^{1 / 4}$ \\
\hline 14 & 444008092423201 & 612781 & $92^{\circ} 42^{\prime} 32^{\prime \prime}$ & $44^{\circ} 40^{\prime} 08^{\prime \prime}$ & T114NR16W23NW1/4SW1/4NE1/4NE1/4 \\
\hline 15 & 444003092425301 & 612780 & $92^{\circ} 42^{\prime} 53^{\prime \prime}$ & $44^{\circ} 40^{\prime} 03^{\prime \prime}$ & 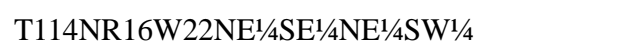 \\
\hline
\end{tabular}


Table 2. Construction information for monitoring wells, Prairie Island Community, Minnesota 1998

\begin{tabular}{|c|c|c|c|c|c|c|c|c|c|}
\hline $\begin{array}{l}\text { Well } \\
\text { (shown } \\
\text { in } \\
\text { figure } \\
\text { 1) }\end{array}$ & Station number & $\begin{array}{l}\text { Date } \\
\text { installed }\end{array}$ & Well casing & Well screen & $\begin{array}{c}\text { Depth of } \\
\text { drilled } \\
\text { hole } \\
\text { (feet } \\
\text { below } \\
\text { land } \\
\text { surface) }\end{array}$ & $\begin{array}{l}\text { Screened } \\
\text { interval } \\
\text { (feet below } \\
\text { land } \\
\text { surface) }\end{array}$ & $\begin{array}{l}\text { Top of } \\
\text { well } \\
\text { casing } \\
\text { above } \\
\text { land } \\
\text { surface } \\
\text { (feet) }\end{array}$ & $\begin{array}{l}\text { Elevation of } \\
\text { top of well } \\
\text { casing } \\
\text { (feet above } \\
\text { sea level) }\end{array}$ & $\begin{array}{l}\text { Elevation of } \\
\text { top of 6- } \\
\text { inch steel } \\
\text { protection } \\
\text { pipe } \\
\text { (feet above } \\
\text { sea level) }\end{array}$ \\
\hline 1 & 443944092421101 & $9 / 3 / 1998$ & $\begin{array}{l}\text { 2-inch, flush-threaded, } \\
\text { schedule } 40 \mathrm{PVC}\end{array}$ & 5-foot, 10-slot PVC & 44.5 & $37.5-41.7$ & 2.85 & 713.32 & 713.63 \\
\hline 2 & 443946092420201 & $9 / 3 / 1998$ & $\begin{array}{l}\text { 2-inch, flush-threaded, } \\
\text { schedule } 40 \text { PVC }\end{array}$ & 5-foot, 10-slot PVC & 33 & $20.3-24.6$ & 2.84 & 695.36 & 695.73 \\
\hline 3 & 444026092433501 & $8 / 31 / 1998$ & $\begin{array}{l}\text { 2-inch, flush-threaded, } \\
\text { schedule } 40 \text { PVC }\end{array}$ & 5-foot, 10-slot PVC & 13.5 & $6.6-10.8$ & 2.80 & 681.31 & 682.08 \\
\hline 4 & 443912092423501 & $8 / 31 / 1998$ & $\begin{array}{l}\text { 2-inch, flush-threaded, } \\
\text { schedule } 40 \text { PVC }\end{array}$ & 5-foot, 10-slot PVC & 19 & $12.1-16.4$ & 3.28 & 688.68 & 689.15 \\
\hline 5 & 443914092422801 & $8 / 31 / 1998$ & $\begin{array}{l}\text { 2-inch, flush-threaded, } \\
\text { schedule } 40 \text { PVC }\end{array}$ & 5-foot, 10-slot PVC & 49.5 & $43.7-48.0$ & 1.75 & 717.36 & 718.23 \\
\hline 6 & 443930092422601 & $9 / 1 / 1998$ & $\begin{array}{l}\text { 2-inch, flush-threaded, } \\
\text { schedule } 40 \text { PVC }\end{array}$ & 5-foot, 10-slot PVC & 49.5 & $44.5-48.8$ & 2.99 & 719.64 & 719.72 \\
\hline 7 & 443941092421801 & $8 / 31 / 1998$ & $\begin{array}{l}\text { 2-inch, flush-threaded, } \\
\text { schedule } 40 \text { PVC }\end{array}$ & 5-foot, 10-slot PVC & 7.5 & $1.9-6.1$ & 2.80 & 677.46 & 677.78 \\
\hline 8 & 443905092420201 & 9/9/1998 & 2-inch, black steel & 5-foot, 10-slot stainless steel & 69.5 & $62.8-67.8$ & 1.96 & 733.48 & 734.04 \\
\hline 9 & 443852092420901 & $8 / 31 / 1998$ & $\begin{array}{l}\text { 2-inch, flush-threaded, } \\
\text { schedule } 40 \text { PVC }\end{array}$ & 5-foot, 10-slot PVC & 19 & $8.3-12.6$ & 2.06 & 683.88 & 684.64 \\
\hline 10 & 443829092411201 & 9/8/1998 & 2-inch, black steel & 5-foot, 10-slot stainless steel & 55 & $49.6-54.6$ & 3.20 & 724.56 & 724.64 \\
\hline 11 & 443843092404301 & $9 / 1 / 1998$ & $\begin{array}{l}\text { 2-inch, flush-threaded, } \\
\text { schedule } 40 \text { PVC }\end{array}$ & 5-foot, 10-slot PVC & 31 & $24.7-28.9$ & 2.83 & 701.06 & 701.14 \\
\hline 12 & 443920092412701 & $9 / .2 / 1998$ & $\begin{array}{l}\text { 2-inch, flush-threaded, } \\
\text { schedule } 40 \text { PVC }\end{array}$ & 5-foot, 10-slot PVC & 24 & $12.9-17.2$ & 2.89 & 689.39 & 689.76 \\
\hline $12 \mathrm{a}$ & 443920092412702 & 9/2/1998 & $\begin{array}{l}\text { 2-inch, flush-threaded, } \\
\text { schedule } 40 \text { PVC }\end{array}$ & 5-foot, 10-slot PVC & 48 & $39.4-43.6$ & 3.06 & 689.58 & 689.95 \\
\hline $12 \mathrm{~b}$ & 443920092412703 & 9/10/1998 & 2-inch, black steel & 5-foot, 10-slot stainless steel & 85 & $68.4-73.4$ & 2.43 & 689.01 & 689.64 \\
\hline 13 & 443901092410001 & 9/2/1998 & $\begin{array}{l}\text { 2-inch, flush-threaded, } \\
\text { schedule } 40 \text { PVC }\end{array}$ & 5-foot, 10-slot PVC & 31.5 & $25.1-29.3$ & 2.80 & 701.96 & 702.56 \\
\hline 14 & 444008092423201 & 9/3/1998 & $\begin{array}{l}\text { 2-inch, flush-threaded, } \\
\text { schedule } 40 \text { PVC }\end{array}$ & 5-foot, 10-slot PVC & 22 & $15.4-19.6$ & 2.93 & 691.09 & 691.57 \\
\hline 15 & 444003092425301 & 9/1/1998 & $\begin{array}{l}\text { 2-inch, flush-threaded, } \\
\text { schedule } 40 \text { PVC }\end{array}$ & 5-foot, 10-slot PVC & 39.5 & $34.9-39.1$ & 2.71 & 709.64 & 710.28 \\
\hline
\end{tabular}




\begin{tabular}{|c|c|}
\hline $\begin{array}{l}\text { Depth } \\
\text { (feet below land } \\
\text { surface) }\end{array}$ & Comments \\
\hline \multicolumn{2}{|r|}{ Well 1} \\
\hline $0-0.5$ & Sandy loam \\
\hline $0.5-4$ & $\begin{array}{l}\text { Poorly-sorted, dark, gray brown, very-coarse sand to pebbles up to } 3 \text { by } 6 \mathrm{~cm} \text {. Subangular to subrounded. Clumped when } \\
\text { squeezed. }\end{array}$ \\
\hline $4-8$ & Moderately poorly sorted, gray brown, subrounded, coarse sand to pebbles up to $1.5 \mathrm{~cm}$. Size gradation is uniform. \\
\hline $8-12$ & Sand \\
\hline & $\begin{array}{l}\text { Hole material at surface when hole depth was } 10 \mathrm{ft} \text {. Poorly sorted, dull, gray-brown, subrounded, medium sand to pebbles up } \\
\text { to } 1 \mathrm{~cm} \text {. Size gradation is uniform. Does not clump when squeezed. }\end{array}$ \\
\hline $12-19$ & Sand and gravel \\
\hline & $\begin{array}{l}\text { Hole material at surface when hole depth was } 15 \mathrm{ft} \text {. Poorly sorted, dull brown or tan, medium sand to pebbles up to } 3 \mathrm{by} 5 \mathrm{~cm} \text {. } \\
\text { Most is very coarse sand. About } 25 \text { percent, by volume, is pebbles larger than } 1-2 \mathrm{~cm} \text {. Subangular to subrounded. }\end{array}$ \\
\hline $19-21$ & Sand \\
\hline $21-44.5$ & Sand and gravel \\
\hline & Water table $36.9 \mathrm{ft}$ below land surface. \\
\hline 44.5 & $\begin{array}{l}\text { Bottom of hole. Sample taken from bottom auger section. Moderately, well-sorted dull brown, medium sand to pebbles up to } \\
2.5 \mathrm{~cm} \text {. Mostly coarse sand. }\end{array}$ \\
\hline \multicolumn{2}{|r|}{ Well 2} \\
\hline $0-3$ & Dark, blackish, silt to fine sand. Clumps when compressed. \\
\hline $3-4$ & Pebbles and cobbles, $1-10 \mathrm{~cm}$. \\
\hline $4-13$ & $\begin{array}{l}\text { Sand and gravel } \\
\text { Hole material at surface when hole depth was } 4 \mathrm{ft} \text {. Moderately poorly sorted, light brown, mixed, coarse sand to pebbles up to } \\
2 \mathrm{~cm} \text {. Mostly clean, very coarse sand less than } 1 \mathrm{~mm} \text {. } \\
\text { Hole material at surface when hole depth was } 9 \mathrm{ft} \text {. Grayish brown, coarse sand to pebbles up to } 4 \mathrm{~cm} \text {. Many pebbles. Mostly } \\
\text { very coarse sand. }\end{array}$ \\
\hline $13-19.5$ & $\begin{array}{l}\text { Sand. } \\
\text { Hole material at surface when hole depth was } 14 \mathrm{ft} \text {. Grayish brown, very coarse sand to pebbles up to } 2 \mathrm{~cm} \text {. About } 80 \text { percent } \\
\text { very coarse sand, sub rounded. } \\
\text { Water table } 18.9 \mathrm{ft} \text { below land surface. }\end{array}$ \\
\hline $19.5-23$ & $\begin{array}{l}\text { Sand and gravel } \\
\text { Hole material at surface when hole depth was } 19.5 \mathrm{ft} \text {. Grayish brown, very coarse sand to pebbles up to } 2 \mathrm{~cm} \text {. About } 80 \text { per- } \\
\text { cent very coarse sand, sub rounded. }\end{array}$ \\
\hline $23-27$ & $\begin{array}{l}\text { Sand. } \\
\text { Hole material at surface when hole depth was } 23 \mathrm{ft} \text {. Moderately well-sorted, light brown, medium sand to small pebbles up to } \\
6 \mathrm{~mm} \text {. Mostly medium sand, subangular. }\end{array}$ \\
\hline $27-27.5$ & Sand and gravel \\
\hline $27.5-33$ & $\begin{array}{l}\text { Sand. } \\
\text { Hole material at surface when hole depth was } 29.5 \mathrm{ft} \text {. Moderately well-sorted, light brown, medium sand to small pebbles up } \\
\text { to } 6 \mathrm{~mm} \text {. Mostly medium sand, subangular }\end{array}$ \\
\hline 33 & Bottom of hole. Sample taken from bottom auger section. Poorly sorted, dark brown, fine sand to granules. \\
\hline
\end{tabular}




\begin{tabular}{|c|c|}
\hline \multicolumn{2}{|r|}{ Well 3} \\
\hline $0-1$ & Black, loamy, topsoil. \\
\hline $1-8$ & $\begin{array}{l}\text { Moderately to poorly sorted, brown, coarse to very coarse sand with pebbles up to } 3 \mathrm{~cm} \text {. } \\
\text { Water table } 5.7 \mathrm{ft} \text { below land surface. }\end{array}$ \\
\hline $8-11$ & Moderately well sorted, light brown, coarse sand to pebbles, well rounded. \\
\hline $11-13.5$ & Well sorted, medium sand to pebbles up to $1.5 \mathrm{~cm}$. \\
\hline 13.5 & $\begin{array}{l}\text { Bottom of hole. Sample taken from bottom auger section. Poorly sorted, grayish-brown, medium, coarse sand and granules, } \\
\text { pebbles up to } 5 \mathrm{~mm} \text {. Sand subrounded, pebbles well rounded. }\end{array}$ \\
\hline \multicolumn{2}{|r|}{ Well 4} \\
\hline $0-1$ & Dark-brown, organic rich, sandy loam. Large pebbles $1 \mathrm{ft}$ down. \\
\hline $1-6$ & $\begin{array}{l}\text { Very dark-brown, moderately poorly-sorted, medium sand to pebbles up to } 3 \text { to } 4 \mathrm{~cm} \text {. Mostly medium sand, some fines. Sub- } \\
\text { rounded. }\end{array}$ \\
\hline $6-6.5$ & Large pebbles, $6 \mathrm{~cm}$, in medium to coarse sand. \\
\hline $6.5-7$ & Well sorted, light brown, coarse sand, some granules up to 4 or $5 \mathrm{~mm}$. \\
\hline $7-19$ & $\begin{array}{l}\text { Tannish-brown, coarse sand to pebbles up to } 5 \mathrm{~cm} \text {. Mostly coarse sand. Subrounded. Pebbles gradually decreased with depth } \\
\text { to very few pebbles. }\end{array}$ \\
\hline & 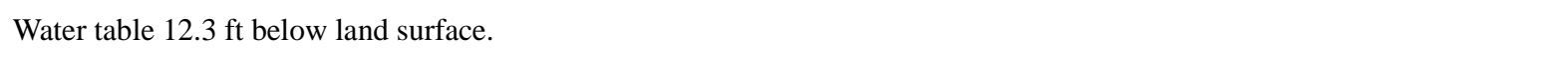 \\
\hline 19 & $\begin{array}{l}\text { Bottom of hole. Sample taken from bottom auger section. Moderately sorted, dark brown, coarse sand to pebbles up to } 1 \text { cm. } \\
\text { About } 80 \text { percent coarse sand. }\end{array}$ \\
\hline
\end{tabular}

Well 5

\begin{tabular}{l|l}
\hline $0-0.5$ & $\begin{array}{l}\text { Dark brown topsoil } \\
0.5-13\end{array}$ \\
$\begin{array}{l}\text { Very well sorted, dark brown, clean, medium sand. } \\
\text { Moderately well sorted, medium brown, medium sand and pebbles up to } 1 \mathrm{~cm} \text {. Mostly medium sand. } \\
\text { Sand }\end{array}$ & $\begin{array}{l}\text { Hole material at surface when hole depth was } 23 \mathrm{ft} . \text { Very well sorted, lighter brown, clean, fine to medium sand. } \\
\text { Hole material at surface when hole depth was } 30 \mathrm{ft} \text {. Light brown, fine to medium sand with granules and pebbles up to } 4 \mathrm{~cm} . \\
\text { Hole material at surface when hole depth was } 40 \mathrm{ft} \text {. Light brown, fine to medium sand with granules and pebbles up to } 2 \mathrm{~cm} \\
\text { Hole material at surface when hole depth was } 45 \mathrm{ft} \text {. Light brown, fine to medium sand. } \\
\text { Water table } 42.5 \mathrm{ft} \text { below land surface. } \\
\text { Bottom of hole. Sample taken from bottom auger section. Moderately sorted, light brown, medium sand to pebbles up to } 4 \\
\text { cm. Sandy diamicton on bit when pulled from hole-poorly sorted, grayed-brown, clay to granule. }\end{array}$ \\
\hline
\end{tabular}

\section{Well 6}

\begin{tabular}{l|l}
$0-1$ & $\begin{array}{l}\text { Topsoil } \\
\text { Moderately poorly sorted, medium brown, medium sand to pebbles up to } 5 \mathrm{~cm} \text {. Mostly coarse and very coarse sand, subangu- } \\
\text { lar to subrounded. } \\
\text { Moderately well sorted, light brown, medium sand to pebbles up to } 1.5 \mathrm{~cm} . \text { About } 70 \text { to } 80 \text { percent very coarse sand, angular } \\
6-17\end{array}$ \\
$\begin{array}{l}\text { to subangular. Pebbles subrounded. } \\
\text { Sand and gravel } \\
18.5-22\end{array}$ & Sand
\end{tabular}

Hole material at surface when hole depth was $19 \mathrm{ft}$. Moderately well sorted, medium brown, medium sand to pebbles up to 1 $\mathrm{cm}$. About 80 to 90 percent coarse sand, subangular to subrounded. 
[ft, feet; cm, centimeter; mm, millimeter; well shown in figure 1]

$22-27$

$27-27.5$

$27.5-30$

$30-49.5$

49.5

Sand and gravel

Hole material at surface when hole depth was $24 \mathrm{ft}$. Moderately well sorted, medium brown, medium sand to pebbles up to 5 $\mathrm{cm}$. About 80 to 90 percent coarse sand, subangular to subrounded. Pebbles occupy about 5 percent by volume.

Gravel

Sand and gravel

Hole material at surface when hole depth was $29 \mathrm{ft}$. Moderately well sorted, medium brown, medium sand to pebbles up to 5 $\mathrm{cm}$. About 80 to 90 percent coarse sand, subangular to subrounded. Pebbles occupy about 5 percent by volume.

Sand

Hole material at surface when hole depth was $39 \mathrm{ft}$. Moderately well sorted, medium brown, medium sand to pebbles up to $2.5 \mathrm{~cm}$. About 80 to 90 percent coarse sand, subangular to subrounded. Pebbles occupy about 5 percent by volume.

Water table $43.5 \mathrm{ft}$ below land surface.

Bottom of hole. Sample taken from bottom auger section. Well sorted, brown, coarse sand to pebbles up to $1 \mathrm{~cm}$. Mostly coarse and very coarse sand. Subangular to subrounded.

\section{Well 7}

\begin{tabular}{l|l}
\hline $0-3$ & $\begin{array}{l}\text { Moderately well sorted, Grayish-brown, very clean, subrounded, coarse sand and gravel with pebbles up to } 2.5 \mathrm{~cm} . \text { Large } \\
\text { cobbles on surface from grave-pit operation. } \\
3-7.5\end{array}$ \\
$\begin{array}{l}\text { Well sorted, grayish brown, subrounded, medium sand to pebbles up to } 2.5 \mathrm{~cm} . \text { From } 3 \text { to } 7.5 \mathrm{ft} \text { material coarsened with depth } \\
\text { from medium sand to mostly granules. } \\
\text { Water table } 5.2 \mathrm{ft} \text { below land surface. } \\
\text { Bottom of hole. Sample taken from bottom auger section. Poorly sorted, gray brown, clean, coarse sand to pebbles up to } 2.5 \\
\mathrm{~cm} . \text { Angular to subrounded. }\end{array}$ \\
\hline
\end{tabular}

\section{Well 8}

0-3

3-21

21-23

23- 27

27- 27.5

27- 30.5

30.5-50

50-69.5
Well sorted, dark gray, fine sand to coarse sand. About 80 to 90 percent medium sand, clumped when squeezed, held shape.

Well sorted, medium gray brown, fine to medium sand. About 80 to 90 percent medium sand. Clumped when squeezed but fell apart. Subrounded.

Dull ochre, clay or silt to fine sand. Clumped when squeezed, fingerprints left impression in squeezed material.

Well sorted, light-yellow ochre, fine to coarse sand. Almost entirely medium sand, subrounded.

Sand and gravel

Sand

Sand and gravel.

Hole material at surface when hole depth was $34 \mathrm{ft}$. Well sorted, light-yellow ochre, fine to coarse sand, almost entirely medium sand, subrounded.

Many pebbles between 35 - $36 \mathrm{ft}$.

Hole material at surface when hole depth was $39.5 \mathrm{ft}$. Moderately well-mixed, medium grayed brown, very fine sand to pebbles up to $1.5 \mathrm{~cm}$. Mostly medium sand, clumps when squeezed but breaks apart, subrounded.

Many pebbles between $41-43 \mathrm{ft}$.

Hole material at surface when hole depth was $44.5 \mathrm{ft}$. Moderately well-mixed, medium grayed brown, very fine sand to pebbles up to $2 \mathrm{~cm}$. Mostly medium sand, clumps when squeezed but breaks apart, subrounded. About 10 percent pebbles.

Hole material at surface when hole depth was $49.5 \mathrm{ft}$. Poorly sorted, dull gray brown, subrounded, medium sand to pebbles up to $2.5 \mathrm{~cm}$, dull gray brown. Mostly medium to coarse sand.

Sand

Hole material at surface when hole depth was $54 \mathrm{ft}$. Poorly sorted, dull gray brown, subrounded, medium sand to pebbles up to $2.5 \mathrm{~cm}$., Mostly medium to coarse sand. Material has more small pebbles and granules than at $49.5 \mathrm{ft}$. 
[ft, feet; cm, centimeter; mm, millimeter; well shown in figure 1]

Water table $58.3 \mathrm{ft}$ below land surface.

Hole material at surface when hole depth was $59.5 \mathrm{ft}$. Poorly sorted, gray brown, subrounded, medium sand to pebbles up to 5 $\mathrm{cm}$.

Hole material at surface when hole depth was $65 \mathrm{ft}$. Poorly sorted, gray brown, subrounded, medium sand to pebbles up to 2 $\mathrm{cm}$, subrounded. Soil is coarser than at $59.5 \mathrm{ft}$.

Hole material at surface when hole depth was $69.5 \mathrm{ft}$. Poorly sorted, gray brown, subrounded, medium sand to pebbles up to 2 by $4.5 \mathrm{~cm}$. Soil is about one-quarter pebbles.

Bottom of hole. Sample taken from bottom auger section. Poorly sorted, dark gray brown, clean, medium sand to pebbles up to $1 \mathrm{~cm}$. Subangular to subrounded.

\section{Well 9}

\begin{tabular}{l|l}
\hline $0-0.5$ & $\begin{array}{l}\text { Dark, gray-brown, sandy loam. } \\
0.5-4\end{array}$ \\
$4-14$ & $\begin{array}{l}\text { Moderately well sorted, dark brown, medium sand to pebbles up to } 1.5 \mathrm{~cm} . \text { Mostly coarse sand. } \\
\text { boderately well sorted, medium sand to granules with some pebbles. Color changed gradually from dark brown to light } \\
\text { brown with depth. At } 4 \mathrm{ft} \text { pebbles up to } 4 \mathrm{~cm} . \text { At } 10 \mathrm{ft} \text { pebbles only } 0.5 \mathrm{~cm} .\end{array}$ \\
$14-18$ & $\begin{array}{l}\text { Well sorted, brown, subrounded, medium sand to granules. Mostly very coarse sand. } \\
18\end{array}$ \\
$\begin{array}{l}\text { Layer of large gravel } \\
\text { Bottom of hole. Sample taken from bottom auger section. Well sorted, subrounded, very clean granules } 1-2 \mathrm{~mm} \text { with pebbles } \\
\text { up to } 1 \mathrm{~cm} .\end{array}$ \\
\hline
\end{tabular}

\section{Well 10}

\begin{tabular}{|c|c|}
\hline $0-1$ & Medium to coarse sand. \\
\hline $1-31.5$ & $\begin{array}{l}\text { Moderately well sorted, light gray brown, subangular to subrounded, fine to coarse sand. About } 90 \text { percent medium sand. } \\
\text { Clumps when squeezed but breaks apart right away. }\end{array}$ \\
\hline $31.5-42$ & Sand and gravel. \\
\hline $42-49.5$ & Sand \\
\hline $31.5-42$ & $\begin{array}{l}\text { Hole material at surface when hole depth was } 31.5 \text { through } 42 \mathrm{ft} \text {. Moderately well-sorted, light gray brown, fine sand to peb- } \\
\text { bles up to } 2.5 \text { by } 3.5 \mathrm{~cm} \text {. Mostly medium to small coarse sand. About } 20 \text { percent pebbles. }\end{array}$ \\
\hline $42-49.5$ & $\begin{array}{l}\text { Sand } \\
\text { Water table } 47.7 \mathrm{ft} \text { below land surface. }\end{array}$ \\
\hline $49.5-54$ & $\begin{array}{l}\text { Sand and gravel } \\
\text { Hole material at surface when hole depth was } 49.5 \mathrm{ft} \text {. Moderately well sorted, light gray brown, subrounded, fine sand to peb- } \\
\text { bles up to } 0.5 \text { by } 1 \mathrm{~cm} \text {. Mostly medium sand, some coarse, very coarse sand, and granules present. }\end{array}$ \\
\hline 55 & $\begin{array}{l}\text { Bottom of hole. Sample taken from bottom auger section. Very poorly sorted, gray, clean, subrounded, medium sand to peb- } \\
\text { bles up to } 4 \mathrm{~cm} \text {. About half is pebble sized. }\end{array}$ \\
\hline
\end{tabular}

\section{Well 11}

0-6

$6.5-20.5$

20.5-23

23-31

31
Well sorted, dark gray brown, subrounded to rounded, very fine to medium sand, clumps when squeezed but breaks apart easily after squeezing.

Well sorted, light brown, well sorted, subrounded to rounded, very fine to medium sand; clumps when squeezed but breaks right away. Appears to be mostly quartz.

Sand and gravel

Sand

Water table $23.9 \mathrm{ft}$ below land surface.

Bottom of hole. Sample taken from bottom auger section. Very well sorted, brown, clean, subrounded, coarse sand. 


\section{Well 12}

\begin{tabular}{l|l}
\hline $0-1.5$ & $\begin{array}{l}\text { Dark brown, sandy loam. } \\
1.5-8.5\end{array}$ \\
$8.5-14$ & $\begin{array}{l}\text { Moderately sorted, reddish brown, coarse sand to pebbles up to } 5 \mathrm{~cm} \text {. Mostly granules about } 1 \mathrm{~mm} . \\
\text { Moderately sorted, medium reddish brown, subangular, very coarse sand to pebbles up to } 2 \mathrm{~cm} . \text { Mostly granules } 1 \mathrm{~mm}, \text { some }\end{array}$ \\
& $\begin{array}{l}\text { Water table } 13.0 \mathrm{ft} \text { below land surface. } \\
\text { Coarse sand and granules. Color has lightened to light brown. Pebbles now } 1.5 \mathrm{~cm} \text { at largest. } \\
14-19\end{array}$ \\
$\begin{array}{l}\text { Hole material at surface when hole depth was } 19 \mathrm{ft} . \text { Almost entirely very coarse sand and small granules. } \\
\text { Bottom of hole. Sample taken from bottom auger section. Well sorted, tan, medium sand to granules. Mostly coarse and very } \\
\text { coarse sand. Granules up to } 2 \mathrm{~mm} .\end{array}$ \\
\hline
\end{tabular}

\begin{tabular}{|c|c|}
\hline \multicolumn{2}{|r|}{ Well 12a } \\
\hline $0-1$ & Topsoil \\
\hline $1-4$ & $\begin{array}{l}\text { Poorly sorted, dark brown, clay or silt to pebbles up to } 5 \text { to } 10 \mathrm{~cm} \text {. Many pebbles. Pebbles angular to rounded, rest of soil sub- } \\
\text { angular. Compacts into ball when squeezed. }\end{array}$ \\
\hline $4-18$ & $\begin{array}{l}\text { Moderately sorted, reddish brown, subangular, coarse sand to pebbles up to } 2 \mathrm{~cm} \text {. Mostly very coarse sand. } \\
\text { Water table } 13.2 \mathrm{ft} \text { below land surface. }\end{array}$ \\
\hline $18-26$ & Well sorted, light brown or tan, very clean, subrounded, medium to coarse sand, some granules. \\
\hline 26 & Layer of pebbles. \\
\hline $26-35$ & $\begin{array}{l}\text { Sand } \\
\text { Material at surface when hole depth was } 34.5 \mathrm{ft} \text {. Well sorted, light brown or tan, very clean, subrounded, medium to coarse } \\
\text { sand, some granules. }\end{array}$ \\
\hline $35-36$ & Pebbles and cobbles. \\
\hline $36-40$ & A layer of fine to very fine sand between 36 - $40 \mathrm{ft}$. Cleared out pilot bit and reaugered in same hole. \\
\hline $40-47$ & Sand \\
\hline $47-48$ & Sand and gravel \\
\hline 48 & $\begin{array}{l}\text { Bottom of hole. Sample taken from bottom auger section. Moderately poorly sorted, brown, medium sand to pebbles up to } 1 \\
\mathrm{~cm} \text {. About } 70 \text { percent is medium and coarse sand. }\end{array}$ \\
\hline
\end{tabular}

\section{Well 12b}

\begin{tabular}{l|l}
\hline $0-1.5$ & Dark brown, sandy loam \\
$1.5-4.5$ & Poorly sorted, darkish gray brown, subangular to subrounded, medium sand to pebbles up to $4 \mathrm{~cm}$. \\
$4.5-36.5$ & Sand
\end{tabular}

Hole material at surface when hole depth was $4.5 \mathrm{ft}$. Moderately sorted, gray brown, clean, subangular to subrounded, medium sand to pebbles up to $1 \mathrm{~cm}$. About 80 percent very coarse sand and granule.

Water table $13.2 \mathrm{ft}$ below land surface.

Hole material at surface when hole depth was $14.5 \mathrm{ft}$. Moderately well sorted, medium brown, coarse sand to pebbles up to $1 /$ $2 \mathrm{~cm}$. About $80-80$ percent is very coarse sand.

Hole material at surface when hole depth was $19.5 \mathrm{ft}$. Moderately well sorted, medium brown, clean, subrounded, medium sand to pebbles up to $1 / 2 \mathrm{~cm}$. About 80 to 80 percent in medium sand to coarse sand range.

Hole material at surface when hole depth was $24.5 \mathrm{ft}$. Well sorted, medium dull brown, clean, subrounded to rounded, fine sand to pebbles up to $0.75 \mathrm{~cm}$. About 80 to 90 percent is medium sand to small coarse sand.

A layer of pebbles at $27 \mathrm{ft}$. 
[ft, feet; cm, centimeter; mm, millimeter; well shown in figure 1]

Hole material at surface when hole depth was $29.5 \mathrm{ft}$. Well sorted, gray-brown, clean, subrounded to rounded, fine or very fine sand to granules up to $4 \mathrm{~mm}$. About 70 percent is fine sand.

Occasional rocks at $33 \mathrm{ft}$.

Hole material at surface when hole depth was $34.5 \mathrm{ft}$. Well sorted, gray brown, clean, subrounded to rounded, very fine sand to granules up to $2 \mathrm{~mm}$. About 80 percent is fine sand.

36.5-38.5 $\quad$ Gravel and sand

Hole material at surface when hole depth was $39.5 \mathrm{ft}$. Well sorted, gray brown, clean, subrounded to rounded, very fine sand to granules up to $2 \mathrm{~mm}$. About 80 percent is fine sand.

$38.5-85$

Sand

Hole material at surface when hole depth was $44.5 \mathrm{ft}$. Well sorted, gray brown, very fine sand to pebbles up to $0.75 \mathrm{~cm}$. Mostly fine sand, clean, subrounded to rounded.

Hole material at surface when hole depth was $49.5 \mathrm{ft}$. Well sorted, gray brown, very fine sand to pebbles up to $0.75 \mathrm{~cm}$. Mostly fine sand, clean, subrounded to rounded.

Hole material at surface when hole depth was $54.5 \mathrm{ft}$. Moderately sorted, gray brown, clean, subrounded, fine sand to pebbles up to $1 / 2 \mathrm{~cm}$. Coarser than before. About equal amounts of fine, medium, and coarse sand, which accounts for bulk (about 80 percent) of soil.

Hole material at surface when hole depth was $59.5 \mathrm{ft}$. Moderately poorly sorted, gray brown, clean, fine sand to pebbles up to $1.5 \mathrm{~cm}$. Coarser than before. More coarse sand and granules.

Hole material at surface when hole depth was $64.5 \mathrm{ft}$. Poorly sorted, gray brown, clean, subrounded, fine sand to pebbles up to $2 \mathrm{~cm}$. Coarser than before, more coarse sand, granules, and pebbles.

Hole material at surface when hole depth was $69.5 \mathrm{ft}$. Poorly sorted, gray brown, clean, subrounded, fine sand to pebbles up to $2 \mathrm{~cm}$. Coarser than before, more coarse sand, granules, and pebbles.

Hole material at surface when hole depth was $74.5 \mathrm{ft}$. Poorly sorted, gray brown, subrounded, medium sand to pebbles up to 3 $\mathrm{cm}$. About 25 to 30 percent or more pebble sized, rest about equal mixtures of medium, coarse, very coarse sand.

Hole material at surface when hole depth was $79.5 \mathrm{ft}$. Poorly sorted, gray brown, clean, subrounded to rounded, fine sand to pebbles up to $4 \mathrm{~cm}$. About 25 to 30 percent pebbles.

Hole material at surface when hole depth was $84.5 \mathrm{ft}$. Poorly sorted, gray brown, clean, subrounded to rounded, fine sand to pebbles up to $4 \mathrm{~cm}$. About 25 to 30 percent pebbles.

Bottom of hole. Sample taken from bottom auger section. Moderately well sorted, brown, subrounded, medium to very coarse sand. About 95 percent is coarse sand.

\begin{tabular}{|c|c|}
\hline \multicolumn{2}{|r|}{ Well 13} \\
\hline $0-2.5$ & Sandy loam \\
\hline $2.5-3$ & Moderately well sorted, light reddish brown, clay or silt to very fine sand. Clumps when squeezed. Clumps do not break apart. \\
\hline $3-14$ & $\begin{array}{l}\text { Poorly sorted, light reddish brown, fine sand to pebbles up to } 2 \text { by } 4 \mathrm{~cm} \text {. Mostly granular, } 1 \text { to } 2 \mathrm{~mm} \text { in size. Granules suban- } \\
\text { gular, pebbles rounded. }\end{array}$ \\
\hline $14-31.5$ & Sand \\
\hline & $\begin{array}{l}\text { Hole material at surface when hole depth was } 14 \mathrm{ft} \text {. Poorly sorted, light brown, clean, subangular to subrounded, coarse sand } \\
\text { to pebbles up to } 1 \text { by } 2 \mathrm{~cm} \text {. Mostly granules. }\end{array}$ \\
\hline & Water table $24.9 \mathrm{ft}$ below land surface. \\
\hline 31.5 & $\begin{array}{l}\text { Bottom of hole. Sample taken from bottom auger section. Moderately well sorted, dull brown, subrounded, coarse sand to } \\
\text { pebbles up to } 1 \mathrm{~cm} \text {. About } 80 \text { to } 90 \text { percent is very coarse sand. }\end{array}$ \\
\hline
\end{tabular}


[ft, feet; cm, centimeter; mm, millimeter; well shown in figure 1]

\section{Well 14}

\begin{tabular}{|c|c|}
\hline $0-0.5$ & Black topsoil \\
\hline $0.5-8$ & $\begin{array}{l}\text { Poorly sorted, light gray brown, coarse sand to pebbles up to } 2 \text { by } 5 \mathrm{~cm} \text {. Pebbles rounded or subrounded. Soil is silty or } \\
\text { clayey; when squeezed it clumps then breaks into large pieces. }\end{array}$ \\
\hline $8-10$ & $\begin{array}{l}\text { Very poorly sorted, gray brown, subangular to subrounded, silt to large pebbles up to } 10 \mathrm{~cm} \text {. About half pebbles, } 2 \mathrm{~cm} \text { and } \\
\text { larger, most of the remaining soil is very coarse sand and granules. }\end{array}$ \\
\hline \multirow[t]{2}{*}{$10-16$} & $\begin{array}{l}\text { Poorly sorted, dark gray brown, very coarse sand to pebbles up to } 5 \mathrm{~cm} \text {. About } 80 \text { percent pebbles } 2-5 \mathrm{~cm} \text {. Rest very coarse } \\
\text { sand and granules. Pebbles rounded. Sand and granules subangular and dirty. }\end{array}$ \\
\hline & Water table $14.6 \mathrm{ft}$ below land surface. \\
\hline $16-22$ & $\begin{array}{l}\text { Moderately well sorted, gray brown, medium sand to pebbles up to } 1.5 \mathrm{~cm} \text {. Only few pebbles, about equal amounts of gran- } \\
\text { ules up to } 4 \mathrm{~mm} \text { and coarse sand. These two comprise about } 80 \text { percent of the material. }\end{array}$ \\
\hline 22 & $\begin{array}{l}\text { Bottom of hole. Sample taken from bottom auger section. Very poorly sorted, gray brown, angular to subrounded, medium } \\
\text { sand to pebbles up to } 2.5 \mathrm{~cm} \text {. }\end{array}$ \\
\hline
\end{tabular}

\section{Well 15}

\begin{tabular}{l|l}
\hline $0-2$ & $\begin{array}{l}\text { Poorly sorted, gray brown, fine to medium sand. Clumps when squeezed and holds shape. } \\
\text { Layer of gravel }\end{array}$ \\
$2-6$ & Ochre or tannish brown, subangular to subrounded, very fine sand. Clumps when squeezed and holds shape.
\end{tabular}

$6 \quad$ Layer of pebbles 2 to $6 \mathrm{~cm}$ in diameter.

6-12 Very well sorted, dark gray brown, subangular, very damp, coarse to very coarse sand. Occasional pebbles 0.5 to $1 \mathrm{~cm}$.

12-19.5 Sand and gravel.

Large flat pebbles up to $6 \mathrm{~cm}$ in diameter being brought up with the sand when depth was $12-14.5 \mathrm{ft}$.

Hole material at surface when hole depth was $14.5 \mathrm{ft}$. Well sorted, medium red brown, coarse to very coarse sand with an occasional granule.

Hole material at surface when hole depth was $19 \mathrm{ft}$. Mixture of medium to coarse sand and pebbles and cobbles. The pebbles and cobbles range from $3-8 \mathrm{~cm}$. The pebbles and cobbles account for about 10 to 30 percent of total material.

\section{5-26.5 Sand}

Hole material at surface when hole depth was $24.5 \mathrm{ft}$. Very poorly sorted, gray brown, medium sand to pebbles. The pebbles range in size from $2 \mathrm{~cm}$ to about $5-6 \mathrm{~cm}$. About half the material is pebbles.

Sand and gravel.

Sand

Hole material at surface when hole depth was $29.5 \mathrm{ft}$. Moderately sorted, gray brown, medium sand to pebbles up to $6 \mathrm{~mm}$. Majority of material appears to be coarse sand, subangular.

Water table $34.1 \mathrm{ft}$ below land surface.

Hole material at surface when hole depth was $34.5 \mathrm{ft}$. Ochre brown, moderately well sorted, fine sand to pebbles up to $1 \mathrm{~cm}$. Most appears to be fine and medium sand.

Layer of pebbles at $37 \mathrm{ft}$.

Bottom of hole. Sample taken from bottom auger section. Poorly sorted, brownish gray, subangular to subrounded, medium sand to pebbles up to $1.5 \mathrm{~cm}$. About 70 percent is in coarse sand range. 
Table 4. Water-quality data collected from monitoring wells, Prairie Island Indian Community, Minnesota, 1998

[mm, millimeter; $\mu \mathrm{S} / \mathrm{cm}$, microSiemens per centimeter; mg, milligrams; $\mu \mathrm{g}$, micrograms; $\mathrm{L}$, liter; ${ }^{\circ} \mathrm{C}$, degrees Celsius, <, less than; E, estimated; --, no data; shaded rows are quality assurance samples]

\begin{tabular}{|c|c|c|c|c|c|c|c|c|c|c|}
\hline $\begin{array}{c}\text { Well } \\
\text { (shown in } \\
\text { figure 1) }\end{array}$ & Station number & Date & $\begin{array}{l}\text { Water } \\
\text { temper- } \\
\text { ature } \\
\text { (degrees } \\
\text { celsius) }\end{array}$ & $\begin{array}{l}\text { Baro- } \\
\text { metric } \\
\text { pressure } \\
(\mathrm{mm} \text { of } \\
\mathrm{Hg})\end{array}$ & $\begin{array}{c}\text { Specific } \\
\text { conductance, } \\
\text { field } \\
\text { measurement } \\
(\mu \mathrm{s} / \mathrm{cm} \text { at } 25 \\
\left.{ }^{\circ} \mathrm{C}\right)\end{array}$ & $\begin{array}{c}\text { Specific } \\
\text { conductance, } \\
\text { laboratory } \\
\text { measurement, } \\
(\mu \mathrm{S} / \mathrm{cm} \text { at } 25 \\
\left.{ }^{\circ} \mathrm{C}\right)\end{array}$ & $\begin{array}{c}\text { Oxygen } \\
\text { dis- } \\
\text { solved } \\
(\mathrm{mg} / \mathrm{L})\end{array}$ & $\begin{array}{l}\mathrm{pH}, \text { field } \\
\text { measure- } \\
\text { ment } \\
\text { (standard } \\
\text { units) }\end{array}$ & $\begin{array}{c}\mathrm{pH}, \\
\text { laboratory } \\
\text { measure- } \\
\text { ment } \\
\text { (standard } \\
\text { units) }\end{array}$ & $\begin{array}{l}\text { Total alkalinity, } \\
\text { dissolved, } \\
\text { incremental } \\
\text { titration, field } \\
\left(\mathrm{mg} / \mathrm{L} \text { as } \mathrm{CaCo}_{3}\right)\end{array}$ \\
\hline 1 & 443944092421101 & $11 / 23 / 98$ & 12.3 & 748 & 466 & 486 & 9.2 & 7.7 & 7.9 & 198 \\
\hline 1 & $\begin{array}{l}443944092421101 \\
\text { Replicate Sample }\end{array}$ & $11 / 23 / 98$ & 12.3 & 748 & 466 & 486 & 9.2 & 7.7 & 7.9 & 198 \\
\hline 2 & 443946092420201 & $11 / 20 / 98$ & 11.4 & 749 & 414 & 420 & 8.0 & 7.6 & 7.8 & 164 \\
\hline 3 & 444026092433501 & $11 / 19 / 98$ & 11.3 & 745 & 677 & 500 & 2.2 & 7.4 & 7.6 & 190 \\
\hline 3 & $\begin{array}{c}444026092433501 \\
\text { Field Blank }\end{array}$ & $11 / 19 / 98$ & -- & -- & -- & 2 & -- & -- & 8.2 & -- \\
\hline 4 & 443912092423501 & $11 / 19 / 98$ & 11.9 & 744 & 753 & 554 & 8.4 & 7.4 & 7.6 & 206 \\
\hline 5 & 443914092422801 & $11 / 30 / 98$ & 10.7 & 747 & 545 & 556 & 8.7 & 7.4 & 7.4 & 225 \\
\hline 6 & 443930092422601 & $11 / 30 / 98$ & 10.1 & 747 & 377 & 394 & 10.1 & 7.7 & 7.7 & 196 \\
\hline 7 & 443941092421801 & $11 / 20 / 98$ & 8.3 & 749 & 232 & 248 & 0.4 & 8.1 & 8.1 & 92 \\
\hline 8 & 443905092420201 & $11 / 30 / 98$ & 11.5 & 747 & 422 & 435 & 8.7 & 7.7 & 7.7 & 158 \\
\hline 9 & 443852092420901 & $11 / 22 / 98$ & 12 & 737 & 590 & 601 & 7.4 & 7.4 & 7.6 & 210 \\
\hline 10 & 443829092411201 & $11 / 23 / 98$ & 12.2 & 748 & 439 & 457 & 9.5 & 8.0 & 8.0 & 110 \\
\hline 11 & 443843092404301 & $11 / 22 / 98$ & -- & 737 & 622 & 495 & -- & 7.6 & 7.6 & 206 \\
\hline 12 & 443920092412701 & $11 / 22 / 98$ & 12.1 & 737 & 482 & 501 & 9.5 & 7.4 & 7.5 & 202 \\
\hline $12 \mathrm{a}$ & 443920092412702 & $11 / 23 / 98$ & 11.3 & 748 & 427 & 448 & 5.1 & 7.8 & 8.0 & 174 \\
\hline $12 b$ & 443920092412703 & $11 / 23 / 98$ & 11.1 & 748 & 500 & 522 & 0.3 & 7.8 & 8.0 & 245 \\
\hline 13 & 443901092410001 & $11 / 22 / 98$ & 11.2 & 737 & 762 & 782 & 6.3 & 7.3 & 7.4 & 237 \\
\hline 14 & 444008092423201 & $11 / 20 / 98$ & 12.2 & 750 & 583 & 596 & 8.6 & 7.3 & 7.5 & 253 \\
\hline 15 & 444003092425301 & $11 / 19 / 98$ & 10.2 & 743 & 332 & 251 & 9.8 & 8.1 & 8.1 & 87 \\
\hline
\end{tabular}


Table 4. Water-quality data collected from monitoring wells, Prairie Island Indian Community, Minnesota, 1998 (Continued)

\begin{tabular}{|c|c|c|c|c|c|c|c|c|c|c|c|}
\hline $\begin{array}{c}\text { Well } \\
\text { (shown in } \\
\text { figure 1) }\end{array}$ & $\begin{array}{c}\text { Acid } \\
\text { neutralizing } \\
\text { capacity, } \\
\text { unfiltered, } \\
\text { titration to } \\
\mathrm{Ph} 4.5 \text {, } \\
\text { laboratory, } \\
(\mathrm{mg} / \mathrm{L} \text { as } \\
\left.\mathrm{CaCO}_{3}\right)\end{array}$ & $\begin{array}{c}\text { Carbonate, } \\
\text { dissolved, } \\
\text { incremental } \\
\text { titration, } \\
\text { field } \\
\text { measure- } \\
\text { ment } \\
(\mathrm{mg} / \mathrm{L} \text { as } \\
\left.\mathrm{CO}_{3}\right)\end{array}$ & $\begin{array}{c}\text { Bicarbonate } \\
\text { dissolved, } \\
\text { incremental } \\
\text { titration, } \\
\text { field } \\
\text { measure- } \\
\text { ment } \\
(\mathrm{mg} / \mathrm{L} \text { as } \\
\left.\mathrm{HCO}_{3}\right)\end{array}$ & $\begin{array}{c}\text { Solids, } \\
\text { residue on } \\
\text { evapo- } \\
\text { ration at } \\
180^{\circ} \mathrm{C}, \\
\text { dissolved } \\
(\mathrm{mg} / \mathrm{L})\end{array}$ & $\begin{array}{l}\text { Nitrogen, } \\
\text { ammonia } \\
\text { dissolved } \\
(\mathrm{mg} / \mathrm{L} \text { As } \\
\mathrm{N})\end{array}$ & $\begin{array}{c}\text { Nitrogen, } \\
\text { nitrite, } \\
\text { dissolved } \\
\text { (mg/L As } \\
\mathrm{N})\end{array}$ & $\begin{array}{l}\text { Nitrogen, } \\
\text { ammonia } \\
\text { plus } \\
\text { organic, } \\
\text { total } \\
\text { (mg/L As } \\
\mathrm{N})\end{array}$ & $\begin{array}{l}\text { Nitrogen, } \\
\text { nitrite } \\
\text { plus } \\
\text { nitrate, } \\
\text { dissolved } \\
(\mathrm{mg} / \mathrm{L} \text { As } \\
\mathrm{N})\end{array}$ & $\begin{array}{c}\text { Phos- } \\
\text { phorus, } \\
\text { total } \\
(\mathrm{mg} / \mathrm{L} \\
\text { As P) }\end{array}$ & $\begin{array}{l}\text { Phos- } \\
\text { phorus, } \\
\text { dissolved } \\
\text { (mg/L As } \\
\text { P) }\end{array}$ & $\begin{array}{c}\text { Phos- } \\
\text { phorus, } \\
\text { ortho- } \\
\text { phos- } \\
\text { phate, } \\
\text { dissolved } \\
\text { (mg/L as } \\
\text { P) }\end{array}$ \\
\hline 1 & 207 & 0 & 241 & 296 & $<0.020$ & $<0.010$ & $<0.10$ & 6.96 & 0.025 & 0.012 & 0.013 \\
\hline 1 & 207 & 0 & 241 & 300 & $<0.020$ & $<0.010$ & $<0.10$ & 7.01 & 0.028 & 0.013 & 0.013 \\
\hline 2 & 171 & 0 & 200 & 256 & $<0.020$ & $<0.010$ & $<0.10$ & 5.42 & 0.011 & 0.013 & 0.014 \\
\hline 3 & 211 & 0 & 232 & 296 & 0.020 & $<0.010$ & 0.10 & 3.13 & $<0.050$ & $<0.050$ & 0.011 \\
\hline 3 & 1.4 & -- & -- & $<10$ & 0.024 & $<0.010$ & $<0.10$ & $<0.050$ & $<0.050$ & $<0.050$ & $<0.010$ \\
\hline 4 & 232 & 0 & 251 & 334 & 0.026 & $<0.010$ & $<0.10$ & 12.4 & 0.010 & 0.010 & 0.011 \\
\hline 5 & 235 & 0 & 274 & 340 & 0.027 & $<0.010$ & $<0.10$ & 4.27 & 0.017 & $<0.050$ & 0.018 \\
\hline 6 & 203 & 0 & 240 & 227 & 0.028 & $<0.010$ & $<0.10$ & 0.770 & $<0.050$ & $<0.050$ & 0.012 \\
\hline 7 & 108 & 0 & 112 & 160 & $<0.020$ & $<0.010$ & $<0.10$ & 2.24 & 0.012 & 0.019 & 0.017 \\
\hline 8 & 168 & 0 & 193 & 263 & 0.033 & $<0.010$ & $<0.10$ & 9.90 & 0.024 & 0.012 & 0.023 \\
\hline 9 & 221 & 0 & 257 & 364 & $<0.020$ & $<0.010$ & 0.10 & 14.4 & $<0.050$ & 0.010 & 0.010 \\
\hline 10 & 118 & 0 & 134 & 315 & 0.021 & $<0.010$ & $<0.10$ & 17.8 & 0.043 & 0.022 & 0.023 \\
\hline 11 & 225 & 0 & 251 & -- & 0.030 & $<0.010$ & $<0.10$ & 5.39 & 0.051 & 0.066 & 0.050 \\
\hline 12 & 226 & 0 & 246 & -- & 0.022 & $<0.010$ & 0.16 & 7.45 & $<0.050$ & 0.014 & 0.013 \\
\hline $12 \mathrm{a}$ & 180 & 0 & 212 & 276 & $<0.020$ & $<0.010$ & 0.14 & 3.53 & 0.033 & 0.011 & 0.014 \\
\hline $12 b$ & 286 & 0 & 299 & 313 & 0.021 & $<0.010$ & 0.25 & $<0.050$ & 0.28 & $<0.050$ & 0.010 \\
\hline 13 & 264 & 0 & 289 & 464 & 0.020 & $<0.010$ & 0.13 & 27.1 & $<0.050$ & $<0.050$ & $<0.010$ \\
\hline 14 & 287 & 0 & 309 & 356 & $<0.020$ & $<0.010$ & $<0.10$ & 5.51 & $<0.050$ & $<0.050$ & $<0.010$ \\
\hline 15 & 98 & 0 & 106 & 156 & 0.023 & 0.017 & $<0.10$ & 5.72 & 0.016 & 0.019 & 0.020 \\
\hline
\end{tabular}


Table 4. Water-quality data collected from monitoring wells, Prairie Island Indian Community, Minnesota, 1998 (Continued)

\begin{tabular}{|c|c|c|c|c|c|c|c|c|c|c|}
\hline $\begin{array}{c}\text { Well } \\
\text { (shown in } \\
\text { figure 1) }\end{array}$ & $\begin{array}{l}\text { Calcium, } \\
\text { dissolved } \\
(\mathrm{mg} / \mathrm{L} \text { as } \\
\mathrm{Ca})\end{array}$ & $\begin{array}{c}\text { Magnesium, } \\
\text { dissolved } \\
(\mathrm{mg} / \mathrm{L} \text { as } \\
\mathrm{Mg})\end{array}$ & $\begin{array}{l}\text { Sodium, } \\
\text { dissolved } \\
(\mathrm{mg} / \mathrm{L} \text { as } \\
\mathrm{Na})\end{array}$ & $\begin{array}{l}\text { Potassium, } \\
\text { dissolved } \\
(\mathrm{mg} / \mathrm{L} \text { as } \mathrm{K})\end{array}$ & $\begin{array}{l}\text { Chloride, } \\
\text { dissolved } \\
(\mathrm{mg} / \mathrm{L} \text { as } \\
\mathrm{Cl})\end{array}$ & $\begin{array}{l}\text { Sulfate, } \\
\text { dissolved } \\
(\mathrm{mg} / \mathrm{L} \text { as } \\
\left.\mathrm{SO}_{4}\right)\end{array}$ & $\begin{array}{l}\text { Fluoride, } \\
\text { dissolved } \\
(\mathrm{mg} / \mathrm{L} \text { as } \\
\mathrm{F})\end{array}$ & $\begin{array}{c}\text { Silica, } \\
\text { dissolved } \\
(\mathrm{mg} / \mathrm{L} \text { as } \\
\left.\mathrm{SiO}_{2}\right)\end{array}$ & $\begin{array}{c}\text { Iron, } \\
\text { dissolved } \\
(\mu \mathrm{g} / \mathrm{L} \text { as } \\
\mathrm{Fe})\end{array}$ & $\begin{array}{c}\text { Manganese, } \\
\text { dissolved } \\
(\mu \mathrm{g} / \mathrm{L} \text { as } \\
\mathrm{Mn})\end{array}$ \\
\hline 1 & 57 & 24 & 2.6 & 1.2 & 5.2 & 16 & $<0.10$ & 22 & $<10$ & $<3.0$ \\
\hline 1 & 57 & 23 & 2.5 & 1.4 & 5.2 & 16 & $<0.10$ & 23 & $<10$ & $<3.0$ \\
\hline 2 & 52 & 20 & 4.7 & 1.7 & 3.0 & 18 & $<0.10$ & 17 & $<10$ & $<3.0$ \\
\hline 3 & 59 & 21 & 9.1 & 0.75 & 12 & 25 & $<0.10$ & 16 & $<10$ & $<3.0$ \\
\hline 3 & 0.13 & 0.13 & E0.59 & $<0.10$ & $<0.10$ & $<0.10$ & $<0.10$ & $<0.10$ & $<10$ & $<3.0$ \\
\hline 4 & 69 & 25 & 2.8 & 0.75 & 5.5 & 6.5 & $<0.10$ & 22 & $<10$ & $<3.0$ \\
\hline 5 & 78 & 21 & 4.6 & 1.5 & 21 & 12 & $<0.10$ & 21 & $<10$ & E2.1 \\
\hline 6 & 51 & 19 & 2.0 & 1.0 & 0.6 & 6.9 & 0.10 & 18 & $<10$ & 4.7 \\
\hline 7 & 31 & 11 & 2.1 & 1.0 & 2.0 & 8.0 & $<0.10$ & 14 & $<10$ & $<3.0$ \\
\hline 8 & 59 & 17 & 2.2 & 1.2 & 8.7 & 8.9 & 0.14 & 25 & E6.9 & 16 \\
\hline 9 & 79 & 24 & 7.9 & 0.94 & 11 & 23 & $<0.10$ & 20 & $<10$ & $<3.0$ \\
\hline 10 & 55 & 17 & 2.3 & 1.1 & 16 & 18 & $<0.10$ & 20 & 18 & 4.9 \\
\hline 11 & 70 & 15 & 11 & 1.3 & 6.5 & 9.2 & $<0.10$ & 25 & $<10$ & E2.5 \\
\hline 12 & 69 & 23 & 3.1 & 0.89 & 2.8 & 10 & $<0.10$ & 21 & $<10$ & 34 \\
\hline $12 \mathrm{a}$ & 53 & 20 & 4.3 & 0.95 & 9.4 & 27 & $<0.10$ & 18 & $<10$ & $<3.0$ \\
\hline $12 \mathrm{~b}$ & 62 & 25 & 7.8 & 1.4 & 11 & 8.7 & $<0.10$ & 18 & 260 & 258 \\
\hline 13 & 97 & 38 & 5.4 & 1.3 & 18 & 21 & $<0.10$ & 17 & $<10$ & $<3.0$ \\
\hline 14 & 81 & 31 & 2.9 & 1.0 & 2.5 & 14 & $<0.10$ & 19 & $<10$ & $<3.0$ \\
\hline 15 & 29 & 10 & 2.1 & 0.90 & 2.0 & 4.6 & $<0.10$ & 18 & $<10$ & E2.5 \\
\hline
\end{tabular}


Table 5. Pesticide data, Prairie Island Indian Community, Minnesota, 1998

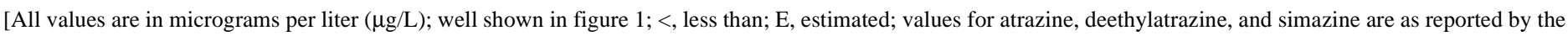
National Water Quality Laboratory. For calculated, corrected values of these compounds see table 8]

\begin{tabular}{|c|c|c|}
\hline Parameter & Well 1 & Well 14 \\
\hline Station Number & 443944092421101 & 444008092423201 \\
\hline Date & $11 / 23 / 98$ & $11 / 20 / 98$ \\
\hline Acetochlor, filtered, recoverable & $<0.05$ & $<0.05$ \\
\hline Alachlor, dissolved, recoverable & $<.05$ & $<.05$ \\
\hline Ametryn, dissolved, recoverable & $<.05$ & $<.05$ \\
\hline Atrazine, dissolved, recoverable & E.085 & E.230 \\
\hline Bromacil, dissolved, recoverable & $<.05$ & $<.05$ \\
\hline Butachlor, dissolved, recoverable & $<.05$ & $<.05$ \\
\hline Butylate, dissolved, recoverable & $<.05$ & $<.05$ \\
\hline Carboxin, dissolved, recoverable & $<.05$ & $<.05$ \\
\hline Cyanazine, dissolved, recoverable & $<.2$ & $<.2$ \\
\hline Cycloate, dissolved, recoverable & $<.05$ & $<.05$ \\
\hline Deethylatrazine, dissolved, recoverable & E.137 & E.473 \\
\hline Deisopropylatrazine, dissolved, recoverable & $<.05$ & $<.05$ \\
\hline Diphenamid, dissolved, recoverable & $<.05$ & $<.05$ \\
\hline Hexazinone, dissolved, recoverable & $<.05$ & $<.05$ \\
\hline Metolachlor, dissolved & $<.05$ & $<.05$ \\
\hline Metribuzin (Sencor), dissolved & $<.05$ & $<.05$ \\
\hline Prometon, dissolved, recoverable & $<.05$ & $<.05$ \\
\hline Prometryn, dissolved, recoverable & $<.05$ & $<.05$ \\
\hline Propachlor, dissolved, recoverable & $<.05$ & $<.05$ \\
\hline Propazine, dissolved, recoverable & $<.05$ & $<.05$ \\
\hline Simetryn, dissolved, recoverable & $<.05$ & $<.05$ \\
\hline Simazine, dissolved, recoverable & E.009 & $<.05$ \\
\hline Terbacil, dissolved, recoverable & $<.05$ & $<.05$ \\
\hline Trifluralin, dissolved, recoverable & $<.05$ & $<.05$ \\
\hline Vernolate, dissolved, recoverable & $<.05$ & $<.05$ \\
\hline
\end{tabular}


Table 6. Relative percent difference between concentrations of constituents in the sample and replicate sample from well 1, Prairie Island Indian Community, Minnesota, 1998

$[\mathrm{mg} / \mathrm{L}$, milligrams per liter; $\mu \mathrm{g} / \mathrm{L}$, micrograms per liter; <, less than; -- , relative percent difference not calculated]

\begin{tabular}{|c|c|c|c|}
\hline Constituent & Sample & $\begin{array}{l}\text { Replicate } \\
\text { sample }\end{array}$ & $\begin{array}{c}\text { Relative } \\
\text { percent } \\
\text { difference } \\
\text { (in percent) }\end{array}$ \\
\hline Nitrogen, ammonia dissolved (mg/L as N) & $<0.020$ & $<0.020$ & -- \\
\hline Nitrogen, nitrite, dissolved ( $\mathrm{mg} / \mathrm{L}$ as $\mathrm{N}$ ) & $<.010$ & $<.010$ & -- \\
\hline Nitrogen, ammonia plus organic, total (mg/L as $N)$ & $<.1$ & $<.1$ & -- \\
\hline Nitrogen, nitrite plus nitrate, dissolved ( $\mathrm{mg} / \mathrm{L}$ as $\mathrm{N}$ ) & 6.96 & 7.01 & -0.71 \\
\hline Phosphorus, total (mg/L as $\mathrm{P}$ ) & .025 & .028 & -11 \\
\hline Phosphorus, dissolved (mg/L as $\mathrm{P}$ ) & .012 & .013 & -8.0 \\
\hline Phosphorus, orthophosphate, dissolved ( $\mathrm{mg} / \mathrm{L}$ as $\mathrm{P}$ ) & .013 & .013 & 0 \\
\hline Calcium, dissolved (mg/L as $\mathrm{Ca}$ ) & 57 & 57 & 0 \\
\hline Magnesium, dissolved ( $\mathrm{mg} / \mathrm{L}$ as $\mathrm{Mg}$ ) & 24 & 23 & 4.3 \\
\hline Sodium, dissolved ( $\mathrm{mg} / \mathrm{L}$ as $\mathrm{Na}$ ) & 2.6 & 2.5 & 3.9 \\
\hline Potassium, dissolved (mg/L as $\mathrm{K}$ ) & 1.2 & 1.4 & -15 \\
\hline Chloride, dissolved ( $\mathrm{mg} / \mathrm{L}$ as $\mathrm{Cl}$ ) & 5.2 & 5.2 & 0 \\
\hline Sulfate, dissolved (mg/L as $\left.\mathrm{SO}_{4}\right)$ & 16 & 16 & 0 \\
\hline Fluoride, dissolved (mg/L as F) & $<.1$ & $<.1$ & -- \\
\hline Silica, dissolved ( $\mathrm{mg} / \mathrm{L}$ as $\left.\mathrm{SiO}_{2}\right)$ & 22 & 23 & 4.4 \\
\hline Iron, dissolved $(\mu \mathrm{g} / \mathrm{L}$ as $\mathrm{Fe})$ & $<10$ & $<10$ & -- \\
\hline Manganese, dissolved ( $\mu \mathrm{g} / \mathrm{L}$ as $\mathrm{Mn})$ & $<3$. & $<3$. & -- \\
\hline
\end{tabular}

Table 7. Results of semiquantitative immunoassay screens for atrazine and related triazine compounds, Prairie Island Indian Community, Minnesota, 1998

\begin{tabular}{ccc}
\hline $\begin{array}{c}\text { Well (shown } \\
\text { in figure 1) }\end{array}$ & Station Number & $\begin{array}{c}\text { Concentration of atrazine and } \\
\text { related triazine compounds }\end{array}$ \\
\hline 1 & 443944092421101 & 0.34 \\
2 & 443946092420201 & .11 \\
3 & 444026092433501 & .12 \\
4 & 443912092423501 & .07 \\
5 & 443914092422801 & .06 \\
6 & 443930092422601 & .06 \\
7 & 443941092421801 & .13 \\
8 & 443905092420201 & .07 \\
9 & 443852092420901 & .16 \\
10 & 443829092411201 & .13 \\
11 & 443843092404301 & .07 \\
12 & 443920092412701 & .26 \\
$12 \mathrm{a}$ & 443920092412702 & .16 \\
$12 \mathrm{~b}$ & 443920092412703 & .21 \\
13 & 443901092410001 & .11 \\
14 & 444008092423201 & .71 \\
15 & 444003092425301 & .17 \\
\hline
\end{tabular}


Table 8. Calculated corrected concentrations for selected triazine herbicides, Prairie Island Indian Community, Minnesota, 1998

[All values in micrograms per liter; wells shown in figure 1]

\begin{tabular}{|c|c|c|c|c|c|c|}
\hline \multicolumn{4}{|c|}{ Surrogate recovery } & \multicolumn{3}{|c|}{ Atrazine compounds } \\
\hline Surrogate & $\begin{array}{l}\text { Concen- } \\
\text { tration } \\
\text { added }\end{array}$ & $\begin{array}{l}\text { Concen- } \\
\text { tration } \\
\text { recovered }\end{array}$ & $\begin{array}{l}\text { Percent } \\
\text { recovered }\end{array}$ & Compound & $\begin{array}{l}\text { Measured } \\
\text { concen- } \\
\text { tration }\end{array}$ & $\begin{array}{c}\text { Corrected } \\
\text { concen- } \\
\text { tration }\end{array}$ \\
\hline \multicolumn{7}{|c|}{ Well 1} \\
\hline d-6-Alpha-HCH & 1.0319 & 0.3902 & 37.8 & Deethylatrazine & 0.1373 & 0.376 \\
\hline d-10-Diazinon & 1.0319 & .3502 & 33.9 & Simazine & .0090 & .025 \\
\hline Terbuthylazine & 1.0319 & .3889 & 37.7 & Atrazine & .0852 & .234 \\
\hline \multicolumn{7}{|c|}{ Well 14} \\
\hline d-6-Alpha-HCH & .9206 & .4390 & 47.7 & Deethylatrazine & .4733 & 1.04 \\
\hline d-10-Diazinon & .9206 & .3758 & 40.8 & Atrazine & .2300 & .51 \\
\hline Terbuthylazine & .9206 & .4341 & 47.2 & & & \\
\hline
\end{tabular}

Table 9. Location and description of surface-water sites, Prairie Island Indian Community, Minnesota, 1998

\begin{tabular}{|c|c|c|c|c|c|}
\hline $\begin{array}{c}\text { Surface- } \\
\text { water site } \\
\text { (shown in } \\
\text { figure 1) }\end{array}$ & $\begin{array}{l}\text { Surface-water } \\
\text { body }\end{array}$ & Description of reference point & $\begin{array}{l}\text { Longitude } \\
\quad \text { (west } \\
\text { longitude) }\end{array}$ & $\begin{array}{c}\text { Latitude } \\
\text { (north latitude) }\end{array}$ & $\begin{array}{c}\text { Elevation of } \\
\text { reference } \\
\text { point (feet } \\
\text { above sea } \\
\text { level) }\end{array}$ \\
\hline A & Vermillion River & $\begin{array}{l}\text { Chiseled square on south bridge rail- } \\
\text { ing of County Road } 18 .\end{array}$ & $92^{\circ} 44^{\prime} 04^{\prime \prime}$ & $44^{\circ} 39^{\prime} 58^{\prime \prime}$ & 694.75 \\
\hline B & Spring Banks Lake & Fence post in Spring Banks Lake & $92^{\circ} 44^{\prime} 02^{\prime \prime}$ & $44^{\circ} 40^{\prime} 15^{\prime \prime}$ & 672.28 \\
\hline $\mathrm{C}$ & North Lake- North & Lag bolt in tree & $92^{\circ} 42^{\prime} 44^{\prime \prime}$ & $44^{\circ} 40^{\prime} 24^{\prime \prime}$ & 677.08 \\
\hline $\mathrm{D}$ & $\begin{array}{l}\text { North Lake- } \\
\text { Middle }\end{array}$ & Lag bolt in tree & $92^{\circ} 41^{\prime} 52^{\prime \prime}$ & $44^{\circ} 39^{\prime} 48^{\prime \prime}$ & 676.69 \\
\hline $\mathrm{E}$ & Nelson Lake & Chiseled square on culvert & $92^{\circ} 40^{\prime} 07^{\prime \prime}$ & $44^{\circ} 37^{\prime} 51^{\prime \prime}$ & 677.87 \\
\hline $\mathrm{F}$ & Larson Lake & $\begin{array}{l}\text { Chiseled square on east bridge rail- } \\
\text { ing of County Road } 18\end{array}$ & $92^{\circ} 40^{\prime} 18^{\prime \prime}$ & $44^{\circ} 37^{\prime} 41^{\prime \prime}$ & 695.10 \\
\hline G & Clear Lake & $\begin{array}{l}\text { U.S. Geological Survey lake gage, } \\
\text { station number } 05346050\end{array}$ & $92^{\circ} 42^{\prime} 36^{\prime \prime}$ & $44^{\circ} 39^{\prime} 13^{\prime \prime}$ & 660.23 \\
\hline $\mathrm{H}$ & Sturgeon Lake & $\begin{array}{l}\text { U.S. Geological Survey lake gage, } \\
\text { station number } 05344850\end{array}$ & $92^{\circ} 38^{\prime} 08^{\prime \prime}$ & $44^{\circ} 38^{\prime} 13^{\prime \prime}$ & 662.84 \\
\hline
\end{tabular}


Table 10. Measured ground- and surface-water altitudes, Prairie Island Indian Community, Minnesota, 1998-99

[--, no data; wells shown in figure 1]

\begin{tabular}{|c|c|c|}
\hline Date & $\begin{array}{l}\text { Water-level altitude, in } \\
\text { feet above sea level }\end{array}$ & Remarks \\
\hline \multicolumn{3}{|c|}{ Well 1} \\
\hline September 3, 1998 & 673.43 & Miscellaneous measurement \\
\hline November 12, 1998 & 673.33 & Miscellaneous measurement \\
\hline February 26, 1999 & 673.10 & Synoptic measurement \\
\hline May 15,1999 & 676.17 & Synoptic measurement \\
\hline July 7, 1999 & 674.62 & Synoptic measurement \\
\hline \multicolumn{3}{|c|}{ Well 2} \\
\hline September 3, 1998 & 673.61 & Miscellaneous measurement \\
\hline November 12, 1998 & 673.46 & Miscellaneous measurement \\
\hline February 26, 1999 & 673.23 & Synoptic measurement \\
\hline May 15, 1999 & 676.68 & Synoptic measurement \\
\hline July 7, 1999 & 674.64 & Synoptic measurement \\
\hline \multicolumn{3}{|c|}{ Well 3} \\
\hline August 31, 1998 & 672.68 & Miscellaneous measurement \\
\hline November 6, 1998 & 672.65 & Miscellaneous measurement \\
\hline February 26, 1999 & 672.49 & Synoptic measurement \\
\hline May 15, 1999 & 678.31 & Synoptic measurement \\
\hline July 7, 1999 & 673.80 & Synoptic measurement \\
\hline \multicolumn{3}{|c|}{ Well 4} \\
\hline August 31, 1998 & 673.06 & Miscellaneous measurement \\
\hline November 6, 1998 & 672.96 & Miscellaneous measurement \\
\hline February 26, 1999 & 672.77 & Synoptic measurement \\
\hline May 15,1999 & 676.51 & Synoptic measurement \\
\hline July 7, 1999 & 674.38 & Synoptic measurement \\
\hline \multicolumn{3}{|c|}{ Well 5} \\
\hline August 31, 1998 & 673.16 & Miscellaneous measurement \\
\hline November 12, 1998 & 673.00 & Miscellaneous measurement \\
\hline February 26, 1999 & 672.83 & Synoptic measurement \\
\hline May 15,1999 & 676.34 & Synoptic measurement \\
\hline July 7, 1999 & 674.45 & Synoptic measurement \\
\hline \multicolumn{3}{|c|}{ Well 6} \\
\hline September 1, 1998 & 673.06 & Miscellaneous measurement \\
\hline November 6, 1998 & 673.02 & Miscellaneous measurement \\
\hline November 12, 1998 & 672.98 & Miscellaneous measurement \\
\hline February 26, 1999 & 672.82 & Synoptic measurement \\
\hline May 15, 1999 & 676.04 & Synoptic measurement \\
\hline July 7, 1999 & 674.46 & Synoptic measurement \\
\hline \multicolumn{3}{|c|}{ Well 7} \\
\hline September 10, 1998 & 673.21 & Miscellaneous measurement \\
\hline November 12, 1998 & 673.23 & Miscellaneous measurement \\
\hline February 26, 1999 & -- & Synoptic measurement, well frozen. \\
\hline May 15,1999 & 675.98 & Synoptic measurement \\
\hline July 7, 1999 & 674.57 & Synoptic measurement \\
\hline
\end{tabular}


Table 10. Measured ground- and surface-water altitudes, Prairie Island Indian Community, Minnesota, 1998-99 (Continued)

[--, no data; wells shown in figure 1]

$\begin{array}{ccc}\text { Water-level altitude, in } & \text { Reet above sea level }\end{array}$

September 9, 1998

November 12, 1998

February 26, 1999

May 15, 1999

July 7, 1999

August 31, 1998

November 6, 1998

February 26, 1999

May 15, 1999

July 7, 1999

September 8, 1998

November 12, 1998

February 26, 1999

May 15, 1999

July 7, 1999

September 1, 1998

November 6, 1998

November 12, 1998

February 26, 1999

May 15, 1999

July 7, 1999

September 2, 1998

November 6, 1998

November 12, 1998

February 26, 1999

May 15, 1999

July 7, 1999

Well 8

673.29

673.22

673.01

676.09

674.40

673.33

673.16

672.96

676.89

674.38

673.61

673.51

673.26

675.83

674.30

674.22

673.80

673.84

673.49

676.86

674.34

673.98

673.72

673.72

673.45

676.46

674.64
Miscellaneous measurement

Miscellaneous measurement

Synoptic measurement

Synoptic measurement

Synoptic measurement

Well 9

Miscellaneous measurement

Miscellaneous measurement

Synoptic measurement

Synoptic measurement

Synoptic measurement

Well 10

Miscellaneous measurement

Miscellaneous measurement

Synoptic measurement

Synoptic measurement

Synoptic measurement

Well 11

Miscellaneous measurement

Miscellaneous measurement

Miscellaneous measurement

Synoptic measurement

Synoptic measurement

Synoptic measurement

Well 12

Miscellaneous measurement

Miscellaneous measurement

Miscellaneous measurement

Synoptic measurement

Synoptic measurement

Synoptic measurement 
Table 10. Measured ground- and surface-water altitudes, Prairie Island Indian Community, Minnesota, 1998-99 (Continued)

[--, no data; wells shown in figure 1]

$\begin{array}{ccc}\text { Water-level altitude, in } & \text { Remarks } \\ \text { feet above sea level }\end{array}$

\begin{tabular}{|c|c|c|}
\hline \multicolumn{3}{|c|}{ Well 12a } \\
\hline September 2, 1998 & 673.31 & Miscellaneous measurement \\
\hline November 6, 1998 & 673.72 & Miscellaneous measurement \\
\hline November 12, 1998 & 673.71 & Miscellaneous measurement \\
\hline February 26, 1999 & 673.45 & Synoptic measurement \\
\hline May 15, 1999 & 676.53 & Synoptic measurement \\
\hline July 7, 1999 & 674.64 & Synoptic measurement \\
\hline \multicolumn{3}{|c|}{ Well 12b } \\
\hline September 10, 1998 & 673.35 & Miscellaneous measurement \\
\hline November 6, 1998 & 673.78 & Miscellaneous measurement \\
\hline November 12, 1998 & 673.73 & Miscellaneous measurement \\
\hline February 26, 1999 & 673.47 & Synoptic measurement \\
\hline May 15, 1999 & 676.56 & Synoptic measurement \\
\hline July 7, 1999 & 674.65 & Synoptic measurement \\
\hline \multicolumn{3}{|c|}{ Well 13} \\
\hline September 2, 1998 & 674.17 & Miscellaneous measurement \\
\hline November 6, 1998 & 673.89 & Miscellaneous measurement \\
\hline November 12, 1998 & 673.93 & Miscellaneous measurement \\
\hline February 26, 1999 & 673.60 & Synoptic measurement \\
\hline May 15, 1999 & 676.78 & Synoptic measurement \\
\hline July 7, 1999 & 674.49 & Synoptic measurement \\
\hline \multicolumn{3}{|c|}{ Well 14} \\
\hline September 3, 1998 & 673.40 & Miscellaneous measurement \\
\hline November 12, 1998 & 673.30 & Miscellaneous measurement \\
\hline February 26, 1999 & 673.04 & Miscellaneous measurement \\
\hline May 15, 1999 & 676.56 & Synoptic measurement \\
\hline July 7, 1999 & 674.57 & Synoptic measurement \\
\hline \multicolumn{3}{|c|}{ Well 15} \\
\hline September 1, 1998 & 672.77 & Miscellaneous measurement \\
\hline November 6, 1998 & 672.80 & Miscellaneous measurement \\
\hline February 26, 1999 & 672.55 & Synoptic measurement \\
\hline May 15, 1999 & 676.14 & Synoptic measurement \\
\hline July 7, 1999 & -- & Synoptic measurement \\
\hline \multicolumn{3}{|c|}{ Vermillion River } \\
\hline \multicolumn{3}{|c|}{ Surface-Water Site A } \\
\hline February 26, 1999 & 693.62 & Synoptic measurement \\
\hline May 15, 1999 & 678.35 & Synoptic measurement \\
\hline July 7, 1999 & 672.43 & Synoptic measurement \\
\hline \multicolumn{3}{|c|}{ Spring Banks Lake } \\
\hline \multicolumn{3}{|c|}{ Surface-Water Site B } \\
\hline February 26, 1999 & 671.12 & Synoptic measurement, Beaver dam downstream \\
\hline May 15, 1999 & 678.44 & Synoptic measurement \\
\hline
\end{tabular}


Table 10. Measured ground- and surface-water altitudes, Prairie Island Indian Community, Minnesota, 1998-99 (Continued)

[--, no data; wells shown in figure 1]

\begin{tabular}{|c|c|c|}
\hline Date & $\begin{array}{l}\text { Water-level altitude, in } \\
\text { feet above sea level }\end{array}$ & Remarks \\
\hline July 7, 1999 & -- & Synoptic measurement \\
\hline \multicolumn{3}{|c|}{ North Lake - North } \\
\hline \multicolumn{3}{|c|}{ Surface-Water Site C } \\
\hline February 26, 1999 & -- & Synoptic measurement, lake frozen. \\
\hline May 15, 1999 & 678.44 & Synoptic measurement \\
\hline July 7, 1999 & 674.79 & Synoptic measurement \\
\hline \multicolumn{3}{|c|}{ North Lake - Middle } \\
\hline \multicolumn{3}{|c|}{ Surface-Water Site D } \\
\hline November 12, 1998 & 674.47 & Miscellaneous measurement \\
\hline February 26, 1999 & -- & Synoptic measurement, lake frozen. \\
\hline May 15, 1999 & 678.25 & Synoptic measurement \\
\hline July 7, 1999 & 674.67 & Synoptic measurement \\
\hline \multicolumn{3}{|c|}{ Nelson Lake } \\
\hline \multicolumn{3}{|c|}{ Surface-Water Site E } \\
\hline February 26, 1999 & -- & Synoptic measurement, lake frozen \\
\hline May 15, 1999 & 677.22 & Synoptic measurement \\
\hline July 7, 1999 & 672.12 & Synoptic measurement \\
\hline \multicolumn{3}{|c|}{ Larson Lake } \\
\hline \multicolumn{3}{|c|}{ Surface-Water Site F } \\
\hline February 26, 1999 & 668.77 & Synoptic measurement \\
\hline May 15,1999 & 677.24 & Synoptic measurement \\
\hline July 7, 1999 & 671.48 & Synoptic measurement \\
\hline \multicolumn{3}{|c|}{ Clear Lake, } \\
\hline \multicolumn{3}{|c|}{ U.S. Geological Survey lake-gage 05346050} \\
\hline \multicolumn{3}{|c|}{ Surface-Water Site G } \\
\hline February 26, 1999 & 668.97 & Synoptic measurement, mean daily stage \\
\hline May 15, 1999 & 675.98 & Synoptic measurement, mean daily stage \\
\hline July 7, 1999 & 672.01 & Synoptic measurement, mean daily stage \\
\hline \multicolumn{3}{|c|}{ Sturgeon Lake } \\
\hline \multicolumn{3}{|c|}{ U.S. Geological Survey lake-gage 05344850} \\
\hline \multicolumn{3}{|c|}{ Surface-Water Site H } \\
\hline February 26, 1999 & 674.02 & Synoptic measurement, mean daily stage \\
\hline May 15, 1999 & 675.84 & Synoptic measurement, mean daily stage \\
\hline July 7, 1999 & 674.30 & Synoptic measurement, mean daily stage \\
\hline
\end{tabular}

